\title{
Immunomodulatory Effects of dsRNA and Its Potential as Vaccine Adjuvant
}

\author{
Bo Jin, ${ }^{1}$ Tao Sun, ${ }^{1}$ Xiao-Hong Yu, ${ }^{1}$ Chao-Qun Liu,, ${ }^{1}$ Ying-Xiang Yang, ${ }^{2}$ Ping Lu, ${ }^{3}$ \\ Shan-Feng Fu, ${ }^{1}$ Hui-Bin Qiu, ${ }^{1}$ and Anthony E. T. Yeo ${ }^{4}$ \\ ${ }^{1}$ Department of Digestive Diseases, Naval General Hospital, 6 Fucheng Rd., Beijing 100048, China \\ ${ }^{2}$ Department of Hepatobiliary Surgery, Naval General Hospital, Beijing 100048, China \\ ${ }^{3}$ Department of Pathology, Naval General Hospital, Beijing 100048, China \\ ${ }^{4}$ Sherman Oaks, CA 91411, USA \\ Correspondence should be addressed to Bo Jin, bjbo.jin@gmail.com
}

Received 31 December 2009; Accepted 9 May 2010

Academic Editor: Zhengguo Xiao

Copyright () 2010 Bo Jin et al. This is an open access article distributed under the Creative Commons Attribution License, which permits unrestricted use, distribution, and reproduction in any medium, provided the original work is properly cited.

dsRNA can be detected by pattern recognition receptors, for example, TLR3, MDA-5, NLRP3 to induce proinflammatory cytokines responsible for innate/adaptive immunity. Recognized by endosomal TLR3 in myeloid DCs (mDCs), dsRNA can activate mDCs into mature antigen presenting cells (mAPCs) which in turn present antigen epitopes with MHC-I molecules to naïve T cells. Coadministration of protein and synthetic dsRNA analogues can elicit an antigen-specific Th1-polarized immune response which stimulates the CD8 ${ }^{+}$CTL response and possibly dampen Th17 response. Synthetic dsRNA analogues have been tested as vaccine adjuvant against viral infections in animal models. However, a dsRNA receptor, TLR3 can be expressed in tumor cells while other members of TLR family, for example, TLR4 and TLR2 have been shown to promote tumor progression, metastasis, and chemoresistance. Thus, the promising potential of dsRNA analogues as a tumor therapeutic vaccine adjuvant should be evaluated cautiously.

\section{Introduction}

Pathogens on invading host cells express molecules that are broadly shared by all microbes and distinct from host. These include lipopolysaccharide, peptidoglycan, flagellin and microbial nucleic acids, and collectively are referred to as pathogen-associated molecular patterns (PAMPs) [1-3]. Pattern recognition receptors (PRRs) of the host when recognizing PAMPs trigger a release of inflammatory cytokines and type I interferons (IFNs) $[4,5]$. PRRs are evolutionally conserved and have been investigated extensively [4]. From the initial investigation of Toll-like receptor (TLR) family [6] to the recent discoveries of retinoic acid-inducible geneI (RIG-I)-like receptors (RLRs) $[7,8]$ and the nucleotidebinding domain and leucine-rich repeat containing gene family (NLRs, also known as NOD-like receptors) $[9,10]$, all the evidence point to an important role in host defense. TLRs are membrane bound receptors that sense PAMPs on the cell surface or in endosomes [11] while RLRs and NLRs recognize microbial molecules in the host cytosol
[12]. The individual members of these PRRs families are characterized by their ligand specificity, cellular localization and activation of unique downstream signaling pathways. Immunity against different microbial pathogen primarily depends on the recognition of the specific PAMP of the pathogen by the corresponding PRR.

Double-stranded RNA (dsRNA), a virus replication intermediate and a signature of infection, is sensed by TLR3, two members of RLRs family, that is, the RNA helicases RIGI and melanoma differentiation-associated gene 5 (MDA-5), and the NLR pyrin domain (NLRP) 3 protein of NLR family. These trigger the release of inflammatory cytokines, that is, activating innate immunity which shapes adaptive immune response $[11,13,14]$. The primary cytokines involved in this response are type I IFNs including IFN- $\alpha$ and IFN- $\beta$ [15].

In this review, the mechanism of innate and adaptive immunity induced by dsRNA and the potential application of dsRNA as a vaccine adjuvant against viral infection and anticancer immunotherapy is elaborated. 


\section{2. dsRNA Induced Signaling}

2.1. The TLR3-Mediated Signaling. TLRs are type I integral membrane glycoproteins which have a trimodular structure composed of an extracellular domain, a single transmembrane domain and an intracellular Toll/IL-1 receptor (TIR) domain $[11,16,17]$. Twelve members of TLR family have been identified in mammals [11]. The extracellular N-terminal domains of TLRs contain 16-28 leucine-rich repeats (LRRs) $[16,18]$ in a horse-shoe structure [17]. Each individual LRR is composed of 20-30 amino acids with a conserved characteristic repetitive sequence pattern rich in leucines, the "LxxLxLxxNxL" motif and two or more repeats in tandem, form curved solenoid structures suitable for protein-protein interactions [19]. The extracellular domain of human TLR3 comprises of 23 LRRs in a horse-shoe shaped structure. The convex face of the extracellular domain of TLR3 is glycosylation-free and contains many positively charged residues while the concave face is largely glycosylated and negatively charged $[20,21]$. The dsRNA binding site of TLR3 is located in two regions near the N-terminus and C-terminus. When dsRNA interacts, two ectodomains of TLR3 are connected by dsRNA in an " $\mathrm{m}$ " shape to form a TLR3-dsRNA 2:1 complex [22]. When combined with TLR3, dsRNA spans the whole " $\mathrm{m}$ " consisting of two "horse-shoes" of the ectodomains of TLR3 (Figure 1A). This satisfies the minimum requirement of $40-50$ base pairs of dsRNA allowing stable binding to TLR3 inducing signaling $[16,23,24]$. With the secondary structure, the transmembrane domain of TLR3 is a single $\alpha$-helix and the endodomain is composed of a five-stranded $\beta$-sheet surrounded by five $\alpha$-helics that forms the TIR domain [25]. The B-B loop that connects $\beta$-strand B with $\alpha$-helix $\mathrm{B}$ in the TIR domain is considered the essential structure that directly interacts with the adaptor protein TIR domaincontaining adaptor inducing IFN- $\beta$ (TRIF) [26]. In addition to the B-B loop, three boxes of conserved residues that reside in TIR domain are involved in TLR3 signaling [25, 27].

TLR3 can be found both intracellularly and on the cell surface in human fibroblasts and epithelial cells. However, it is predominantly located in intracellular vesicles, for example, endosomes, in most cell types including dendritic cells and macrophages [28, 29]. TLR3 is activated by extracellular dsRNA that is released from dsRNA viruses or is produced during single-stranded RNA viruses' replication or comes from application of synthetic dsRNA analogues [4]. It is largely unknown how extracellular dsRNA are delivered to the intracellular vesicles containing TLR3. Studies have suggested that CD14 may play an important role in dsRNA uptake $[20,30]$. Once internalized into the endosome, dsRNA binds to its adaptor protein TLR3 and activates several signaling pathways. Upon binding to dsRNA, the B-B loop of the TLR3 TIR domain combines with TIR domain of TRIF activating several transcription factors, including nuclear factor $-\kappa \mathrm{B}(\mathrm{NF}-\kappa \mathrm{B})$, interferon regulatory factor 3 (IRF3), and activating protein 1 (AP-1) [25].

There are two pathways to activate NF- $\kappa \mathrm{B}$ mediated by receptor-interacting protein 1 (RIP1) and tumor necrosis factor (TNF) receptor-associated factor 6 (TRAF6) (Figure 1A). TRAF6 is a ubiquitin ligase and plays a role in RIP1 polyubiquitination $[31,32]$. Polyubiquitinated RIP1 is recognized by ubiquitin receptors, the transforming growth factor $\beta$-activating kinase (TAK) binding protein (TAB) 2 and 3, which in turn activate TAK1 [33]. I $\kappa$ B kinase-related kinase $\alpha(\mathrm{IKK} \alpha)$ and $\operatorname{IKK} \beta$ are phosphorylated by the activated TAK1. This leads to phosphorylation and degradation of $\mathrm{I} \kappa \mathrm{B}$, an inhibitor of NF- $\kappa \mathrm{B}$, and eventually results in the translocation of NF- $\kappa$ B to cell nucleus. This is followed by the activation of specific gene promoter A20. TAK1 also activates the 2 other classes of kinase, JNK and p38 and these activate the family of AP-1 transcription factors [27]. The third signal comes from TRIF activating IRF3 (Figure 1A). TRIF activates the kinase complex TRAF family member-associated NF$\kappa \mathrm{B}$ activator (TANK)-binding kinase 1 (TBK1) and IKK $\varepsilon$ through its adaptor protein, NF- $\kappa$ B activating kinase (NAK)associated protein 1 (NAP1), leading to the phosphorylation and nuclear translocaton of IRF3 consequently inducing the expression of IFN- $\beta$ [34]. In addition to NAP1, TRAF3 is also part of the TBK1/IKKE complex that is involved in the TRIFmediated IRF3 activation [35]. Another signal from TLR3 is related to the phosphorylation of two specific tyrosine residues $\left(\mathrm{Tyr}^{759}\right.$ and $\mathrm{Tyr}^{858}$ ) in the TLR3 TIR domain when TLR3 interacts with TRIF (Figure 1A). Phosphorylated $\mathrm{Tyr}^{759}$ recruits phosphatidylinositol 3-kinase (PI3K) which then activates kinase Akt required for phosphorylation and activation of IRF3 in nucleus [36]. The phosphorylation of $\mathrm{Tyr}^{759}$ and also $\mathrm{Tyr}^{858}$ results in degradation of $\mathrm{I} \kappa \mathrm{B}$ leading to $\mathrm{NF}-\kappa \mathrm{B}$ release and this induces phosphorylation of NF- $\kappa \mathrm{B}$ which partially activates it [37]. Tyrosine kinase c-Src also plays a role in Akt activation [38]. The unique signal pathway of TRIF is able to induce mammalian cell apoptosis (Figure 1A). TRIF interacts with Fas-associated cell death domain (FADD) protein through RIP1 which in turn activates procaspase- 8 to initiate cell apoptosis $[25,39]$.

2.2. The RLRs-Mediated Signaling. RLRs are cytoplasmic viral RNA sensors with three recognized members including RIG-I, MDA-5 and laboratory of genetics and physiology 2 (LGP2). All belong to the $\mathrm{DExD} / \mathrm{H}$ box RNA helicase family [40]. In addition to the central helicase domain, RIG-I and MDA-5 have two caspase recruitment domains (CARDs) at its N-terminus which are responsible for downstream signaling cascade through the interaction with a CARDcontaining adapter, mitochondrial antiviral signaling adapter (MAVS, also known as IPS-1, VISA, or Cardif) located in the outer mitochondrial membrane [41]. LGP2, lacking the $\mathrm{N}$-terminal CARD, works as a negative regulator of RLRs signaling. Although only a single CARD physically interacts with MAVS, both CARDs are essential for downstream signaling $[42,43]$. The RIG-I activation is self-inhibited by the C-terminal regulatory domain (RD), also referred as the C-terminal domain (CTD) or repressor domain, through intramolecular association between RD and both the CARD and the helicase domains [42-44]. RD is also responsible for the binding affinity to the dsRNA and $5^{\prime}$-triphosphated single-stranded RNA (5' ppp-ssRNA) of viral RNAs with 


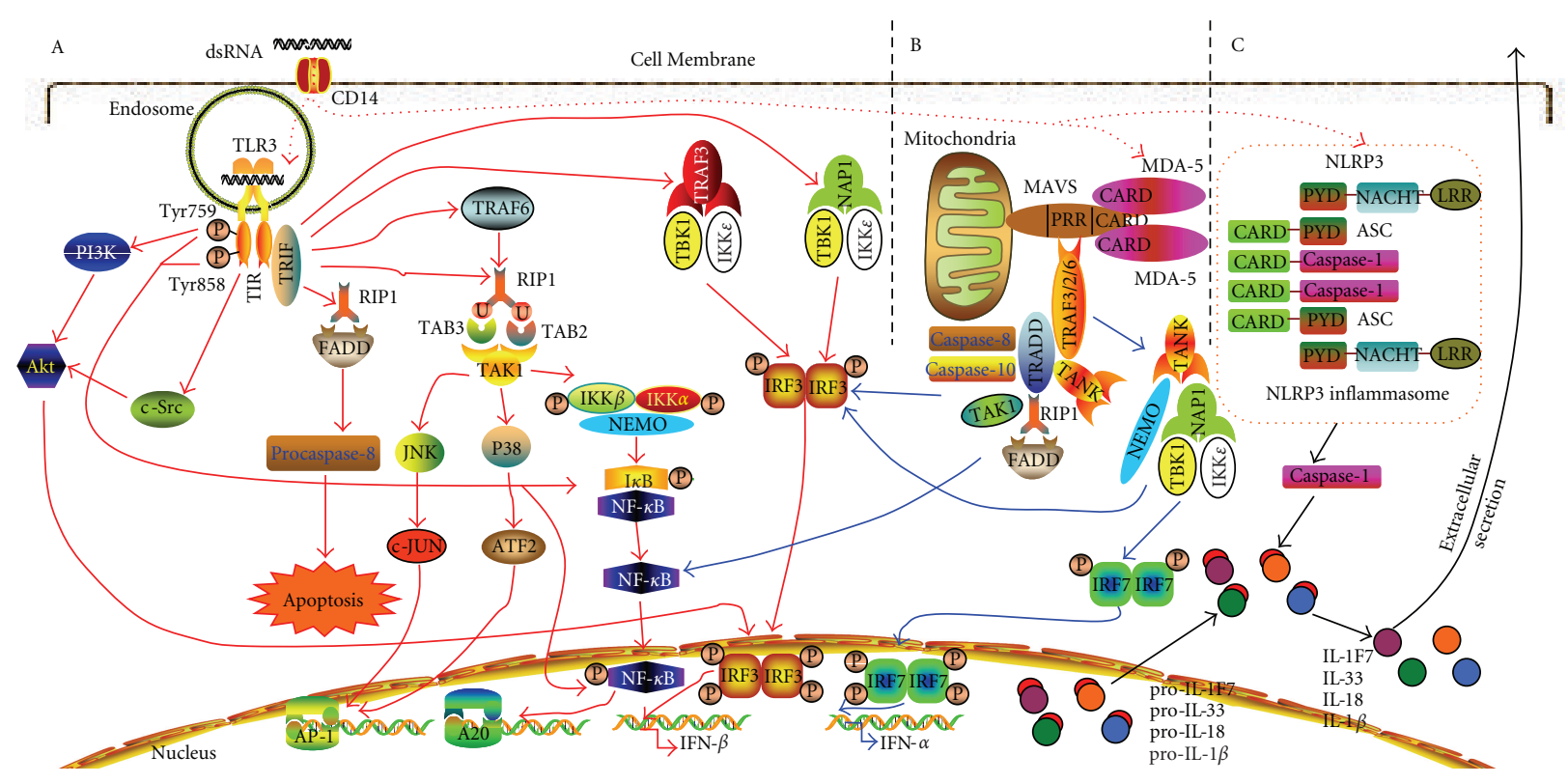

FIGURE 1: dsRNA induced signal pathways. (A) dsRNA signaling through TLR3. dsRNA that is internalized into endosome binds to TLR3. The mechanism of dsRNA internalization is unknown, CD14 may play a role. TLR3 possesses two dsRNA binding sites near the N-terminus and C-terminus. When combined with dsRNA, four dsRNA binding sites from two TLR3 molecules that are linked by the sole dsRNA molecule in an " $m$ " shape, and the B-B loop of the TLR3 TIR domain combines with the TIR domain of TRIF. The interaction of TRIF with RIP1 or TRAF6 results in polyubiquitination of RIP1, the latter binds ubiquitin receptors TAB2 and TAB3 which activates TAK1. Activated TAK1 induces phosphorylation of IKK $\alpha$ and IKK $\beta$ leading to phosphorylation and degradation of I $\kappa$ B. The release and translocation of NF- $\kappa \mathrm{B}$ to cell nucleus then occurs which results in the specific gene promoter A20 being activated. TAK1 also starts an activation sequence beginning with JNK and p38, which activates c-JUN and ATF2 and this activates the AP-1 transcription factors family. TRIF activates TBK1 and IKK $\varepsilon$ through NAP1 and this results in phosphorylation and nuclear translocaton of IRF3 resulting in IFN- $\beta$ production. TRAF3 also binds with the TBK1/IKKe complex inducing IRF3 activation. Combination of TRIF results in phosphorylation of Tyr $\mathrm{r}^{759}$ and Tyr $\mathrm{r}^{858}$ in the TLR3 TIR domain which subsequently induces the phosphorylation of, and degradation of I $\kappa \mathrm{B}$ leading to NF- $\kappa \mathrm{B}$ release. Phosphorylated $\mathrm{Tyr}^{759}$ recruits PI3K and activates kinase Akt for full phosphorylation and activation of IRF3 in nucleus. Tyrosine kinase c-Src also plays a role in Akt activation. TRIF interacts with FADD through RIP1 and activates procaspase-8 to initiate cell apoptosis. (B) dsRNA signaling through MDA-5. dsRNA is recognized by MDA-5 in cytosol. MDA-5 interacts with MAVS located on the outer mitochondrial membrane via CARD-CARD interaction leading to the dimerization of the MAVS N-terminal CARD domains which subsequently binds TRAF3 directly through the interaction between the TRAF domain of TRAF3 and the TRAF-interacting motif in the PRR of MAVS. Then the RING domain of TRAF3 forms a scaffold to assemble the noncanonical IKKs signal complex composed of TANK, TBK1, IKKE, NAP1 and NEMO. This complex activates the signal-dependent phosphorylation of IRF3 and IRF7 to form a functional homodimer or heterodimer which translocate to the nucleus to induce expression of type I IFN. TRAF2 and TRAF6 also associates with MAVS and is involved in activation of P38 MAPK and promotion of IL-12 and type I IFN production or activation of NF- $\kappa \mathrm{B}$, JNK and P38 signaling. In addition, MAVS recruits TRADD and interacts with TRAF3, TANK, FADD and RIP1 to activate both IRF3 and NF- $\kappa$ B signaling. (C) dsRNA signaling through NLRP3 inflammasome. NLRP3 recognizes dsRNA by a series of LRRs at the C-terminus. The NACHT domain at the middle of NLRP3 is related to self-oligomerization and the formation of inflammasome. Studies have suggested dsRNA may activate the NLRP3 inflammasome. Activation of NLRP3 results in the interaction of NLRP3 PYD with ASC PYD, and in turn ASC CARD associates with pro-caspase-1 CARD and thereby assembles the NLRP3 inflammasome. Once incorporated into NLRP3 inflammasome, pro-caspase-1 is activated by proteolytic cleavages to remove the CARD prodomain. The active caspase- 1 in turn cleaves the IL- $1 \beta$, IL-18, IL-33 and IL-1F7 precursors into their active forms and these active cytokines are secreted extracellularly.

a common core RNA binding site specifically adapted to distinct and unique patterns [44-47]. It is also responsible for RIG-I dimerization. MDA-5 RD preferentially binds dsRNA with blunt ends but does not associate with dsRNA with either the $5^{\prime}$ or $3^{\prime}$ overhangs [13]. The central helicase domain displays cooperative RNA binding properties [43, $48,49]$. The RD of MDA-5 does not exhibit self-inhibitory activity $[42,50]$. MDA- 5 is negatively regulated by dihydroxyacetone kinase (DAK) and other possible regulators [51].

RIG-I binds $5^{\prime}$-triphosphate RNA in single- or doublestranded forms [52-54] or short dsRNA of 300-1000 bp without a $5^{\prime}$-triphosphate [54] while MDA-5 recognizes long dsRNA of more than $1000 \mathrm{bp}$ in length and the synthetic dsRNA analogue polyinosinic-polycytidylic acid [poly (I:C)] [54-56]. Upon sensing RNA, both RIG-I and MDA-5 are activated and initiate downstream signaling through the common pathway via adaptor protein MAVS (Figure 1B). MAVS consists of a CARD at the N-terminus, a prolinerich region (PRR) in the middle and a transmembrane domain at the C-terminus attached to the outer surface of mitochondria [57]. Activated RIG-I and MDA-5 associate MAVS via a CARD-CARD interaction which leads to the 
dimerization of the MAVS N-terminal CARD domains. Once activated, binding to TRAF3 occurs directly through the interaction between the TRAF domain of TRAF3 and the TRAF-interacting motif (TIM) in the PRR of MAVS [58-60]. Following the association of TRAF3 with MAVS, the RING domain of TRAF3 forms a scaffold to assemble noncanonical IKKs signal complex composed of TANK, TBK1, IKKe, NAP1 and NF- $\kappa$ B essential modulator (NEMO). This complex then activates the signal-dependent phosphorylation of IRF3 and IRF7 to form a functional homodimer or heterodimer and translocates to the nucleus $[61,62]$. The association of MAVS and TRAF2 or TRAF6 has also similarly been demonstrated [63]. TRAF6 is essential in the activation of NF- $\kappa \mathrm{B}$, JNK and P38 signaling [64] while TRAF2 is involved in activation of P38 MAPK which promotes IL-12 and type I IFN production [65]. Moreover, TNFR-associated death domain (TRADD) is recruited to MAVS following virus infection and interacts with TRAF3, TANK, FADD and RIP1 as well as activating both IRF3 and NF- $\kappa$ B signaling [66]. Another proteintermed stimulator of interferon genes (STING, also known as MITA or MYPS) expressed either on the outer micochondrial membrane [67] or endoplasmic reticulum [68] directly interacts with RIG-I but not MDA-5. It subsequently recruits TBK1 activating IRF-3. STING has been reported to associate with major histocompatibility complex class II (MHC II) and mediates apoptotic signals via ERK activation [69]. It was recently reported that RIG-I binds to an adaptor apoptosis-associated speck-like protein containing a caspaseactivating and recruitment domain (ASC) to trigger caspase1-dependent inflammasome activation by a mechanism independent of MAVS, CARD9 and NLRP3. This suggests that RIG-I is able to activate the inflammasome in response to certain RNA viruses [70].

2.3. The NLRs-Mediated Signaling via Inflammasome. NLRs are intracellular PRRs sensing PAMPs and danger signals or danger-associated molecular patterns (DAMPs) released by injured cells [71]. The NLR family has 23 members in humans and at least 34 members in mice [72]. NLRs are multidomain proteins with tripartite structure composed of an N-terminal effector region, a central NACHT (Neuronal Apoptosis inhibitory protein, NAIP; Class II transactivator, CIITA; plant Het product involved in vegetative incompatibility, HET-E; Telomerase-associated protein 1, TP-1) domain (also known as NOD domain), and a C-terminal region for PAMPs recognition. The $\mathrm{C}$-terminal region is characterized by a series of LRRs and is implicated in ligand sensing and NLRs autoregulation but the precise mechanism is not clear [71]. The NACHT domain is a member of signal transduction ATPases, part of the P-loop NTPase family [73] and is related to self oligomerization and the formation of inflammasome [71]. The $\mathrm{N}$-terminal region contains several protein interaction modules, such as acidic domain, baculoviral inhibitory repeat (BIR)-like domain, CARD and pyrin domain (PYD). Accordingly, NLRs are further divided into subfamilies as NLRA, NLRB, NLRC and NLRP. An additional subfamily, NLRX, is characterized by the presence of an N-terminal domain with no strong homology to any known domains of other NLR subfamily member [74].

Upon recognition of PAMPs, toxins, or danger signals by NLRs, a large protein complex termed the inflammasome composed of NLRs, ASC and pro-caspase- 1 is activated. This protein platform activates pro-caspase- 1 into its active form of caspase- 1 and this hydrolyzes pro-IL-1 $\beta$ and pro-IL-18 into their mature biologically active forms which are secreted extracellularly to play a role in immune response $[14,71]$. Limited studies have suggested dsRNA is an activator of NLRP3 inflammasome [75-78] although this has been disputed [79]. NLRP3 senses PAMPs either from bacteria, such as lipopolysaccharide (LPS), muramyl dipeptide (MDP), bacterial pore-forming toxin and bacterial DNA and RNA, or from viruses such as viral ssRNA or dsRNA, dsRNA analogue poly (I:C). It also senses other compounds such as imidazoquinoline antiviral drugs R837 and R848, nonmicrobial signals encompassing uric acid crystals, calcium pyrophosphate dehydrate (CPPD), asbestos, silica, extracellular ATP, alum adjuvant and fibrillar amyloid- $\beta[14,71,72,80]$. It is believed that NLRP3 activation results in the interaction of NLRP3 PYD with ASC PYD which in turn causes ASC CARD to associate with pro-caspase-1 CARD assembling the NLRP3 inflammasome (Figure 1C) [81]. Besides NLRP3, ASC and pro-casepase-1, human NLRP3 inflammasome contains a CARD-containing protein, CARD inhibitor of NF- $\kappa \mathrm{B}$-activating ligands (Cardinal, also known as CARD8). However, there is no homologue of Cardinal in the mouse [81-83]. Allen et al. (2009) utilized small heteroduplex RNA (shRNA) to knockdown the expressions of ASC, NLRP3 and Cardinal respectively in human THP-1 monocyte cell lines. The IL- $1 \beta$ production triggered by lentivirus infection was significantly attenuated by the addition of shRNA of ASC or NLRP3. In contrast, secretion of IL- $1 \beta$ was not affected by knockdowns of Cardinal. Thus, it has been suggested that Cardinal may not affect NLRP3 inflammasome function [77]. Furthermore, Cardinal does not bind to NLRP3 in the inflammasome [84].

The activation of the NLRP3 inflammasome has been demonstrated through a number of mechanisms. However, the direct ligand for NLRP3 has yet to be defined. It has been proposed that the activation of the NLRP3 inflammasome requires both microbial molecules and a second signal such as extracellular ATP or pore-forming molecules [72]. Alternatively, it has also been suggested that reactive oxygen species (ROS) may be the common NLRP3 inflammasome activator since the most striking features associated with NALP3 activators like potassium efflux and the induction of frustrated phagocytosis all leads to ROS production via NADPH $[71,85,86]$. In particular, the activation of NLRP3 inflammasome triggered by virus infection or by poly (I:C) requires sensing viral RNA or poly (I:C), lysosomal maturation, cathepsin $\mathrm{B}$ and ROS generation [77]. The assembly of NLRP3 inflammasome leads to the activation of pro-caspase- 1 and consequently the maturation of pro-IL-1 $\beta$ and pro-IL-18 (Figure 1C).

Caspases belong to a conserved metazoan aspartatespecific cysteine proteases family with 11 members in human (caspases 1 to 10, and 14) and 10 members in murine species 
(caspases 1, 2, 3, 6, 7, 8, 9, 11, 12, and 14) [87, 88]. All caspases are synthesized as inactive zymogens containing a prodomain and are divided into two subfamilies: initiator caspases and effector caspases based on the length of their prodomains. Initiator caspases (caspases 1, 2, 4, 5, 8, 9, $10,11,12)$ are involved in the interaction with upstream adapter molecules and possess long prodomains that contain either the death effector domain or CARD. Effector caspases (caspases $3,6,7$ ) that possess short prodomains are activated by upstream caspases and are able to cleave multiple cellular substrates involved in apoptosis [87]. Caspase-1, along with caspases $4,5,11$, and 12 are often referred to as proinflammatory caspases. Once incorporated into NLRP3 inflammasome, pro-caspase- 1 is activated by proteolytic cleavage to remove the CARD prodomain. The active caspase- 1 in turn cleaves the IL- $1 \beta$, IL-18, IL-33 and IL-1F7 precursors into their active forms and these active cytokines are secreted extracellularly and become immunoreactive (Figure 1C) [89].

It was recently reported that influenza virus infection results in the activation of NLR inflammasomes in the lung. Although NLRP3 is required for inflammasome activation in certain cell types, adaptive immunity to influenza virus is ASC and caspase-1 dependent rather than NLRP3 dependent, suggesting a central role of ASC inflammasomes. The investigators concluded that influenza virus infection stimulates NLRP3-dependent and NLRP3 independent inflammasomes in a cell type-specific manner [90]. Moreover, it has been suggested that some viral RNA can activate inflammasome via interaction between RIG-I and adaptor ASC independent of NLRP3, MAVS, and CARD [70].

\section{Modulation of Adaptive Immunity by dsRNA}

3.1. Activation of DCs. Activation of dendritic cells (DCs) occurs upon sensing dsRNA [91]. DCs express a repertoire of PRRs including TLRs (TLR3 is not expressed in plasmacytoid DCs), RIG-I and MDA-5 (absent in plasmacytoid DCs), as well as NLRs, and are able to recognize a range of pathogenic microbes [92-94]. The interaction of PAMPs and PRRs on DCs induces the maturation and activation of DCs via transcription, translation and secretion of inflammatory cytokines and chemokines through the signal pathways as described above. The activated DCs, characterized by enhanced antigen presentation capacity and referred to as antigen-presenting cells (APCs), migrate to draining lymph nodes and interact with $\mathrm{T}$ and/or B lymphocytes initiating the immunity process. Among the cytokines triggered and secreted, type I IFN plays a major role in the crosspriming of $\mathrm{CD} 8^{+} \mathrm{T}$-cells by promoting the expression of costimulatory molecules of DCs [95]. The proliferation and differentiation of the lymphocytes are mediated by signals from the activated DCs which comprise of the co-presentation of MHC molecules and pathogen-derived peptides. Additionally, signals from costimulatory molecules including CD80 and CD86, as well as the instructional signals, for example, IL-12p70 for Th1, IL-4 for Th2, and
IL-6 and IL-23 for Th17 from the presenting DCs [91] are also present. dsRNA receptors which include TLR3 and RIG-I/MDA-5 are expressed in myeloid DCs (mDCs) and primarily produce IL-12 and IFN- $\beta$ when recognition of dsRNA occurs [94]. However, poly (I:C) with different molecular weights have differential effects on the maturation of DCs [96]. Interestingly, co-culture of bone marrowderived DCs with protein and poly (I:C) reduced the antigen uptake by DCs. However, the reduced uptake of antigen did not affect CTL priming by DCs suggesting that the reduction in uptake of soluble antigen in the presence of poly (I:C) is independent of TLR-mediated DC activation [97].

3.2. Activation of Th1 Cells. Newly primed $\mathrm{CD} 4^{+}$T-cells are programmed by various cytokines and other factors from DCs and other innate immune cells to differentiate into Th1 or Th2 or Th17 effector cells or regulatory T-cells (Treg) [98]. Th1 lymphocytes are produced by the naïve $\mathrm{CD} 4^{+} \mathrm{T}$-cells (Th0) interacting with IL-12 from mDCs to stimulate the expression of signal transducer and activator of transcription (STAT) 1 and subsequently that of $\mathrm{T}$ box expressed in $\mathrm{T}$ cells (T-bet). The latter is the critical transcription factor of Th1 cells [99]. Activated Th1 cells produce cytokines like IL- 2 and IFN- $\gamma$ that are cofactors in CD $8^{+}$CTLs activation and synergistically activate mDCs acting via a feedback loop. Signals from Th1 cells are essential for $\mathrm{CD}^{+} \mathrm{T}$-cell proliferation and function [99]. It is believed that dsRNA is capable of inducing robust IL-12p70 production which reduces the threshold of Th1 response and herein promotes Th1-biased adaptive immunity through TLR3 and JNK pathways $[98,100]$. TNF- $\alpha$, type I IFN and IL-18 also play important roles in the induction of Th1 response by dsRNA [101]. Type I IFN can activate mDCs directly by inducing phenotypic maturation which includes but is not restricted to upregulation of MHC Class I, class II, CD40, CD80, CD86 and higher expression of CD83 [102]. Besides inducing mDCs maturation and activation, IFN- $\alpha / \beta$ upregulates the expression of chemokine receptor CCR7 to sensitize mDCs to CCL19 and CCL21 which promote the migration of mDCs from peripheral tissues towards the T-cell area of lymphoid organs [102]. Type I IFN is also necessary for the generation of a Th1 $\mathrm{CD}^{+}$adaptive T-cell response whereas IL-12p40 and type II IFN are not. Therefore, the activation of Th1 cell response induced by dsRNA is possibly mediated by its capacity of inducing robust type I IFN production [92]. However, at low concentrations of dsRNA $(0.1-1 \mu \mathrm{g} / \mathrm{ml})$, human lymphocytes express prototypic Th2 cytokine IL-4 [103]. Indeed, when coadministered with protein antigen, in addition to the induction of robust Th1 biased immunity, dsRNA is also capable of enhancing Th2 antigen-specific immune response [104-106].

3.3. Activation of Cytotoxic T Lymphocytes. When stimulated by dsRNA along with specific antigen, activated DCs are able to induce antigen-specific $\mathrm{CD}^{+}$cytotoxic $\mathrm{T}$ lymphocytes (CTLs) activation through cross-presentation and crosspriming mechanism [91]. During viral infection of mDCs, dsRNA is produced during replication in the infected mDCs 
and the latter in turn activates mDCs through TRIF, MAVS, NLRP3 inflammasome and possibly another undefined signal pathway(s) to become APCs. APCs present endogenous antigens including those from intracellular viral origin with MHC class I molecules to naïve $\mathrm{CD} 8^{+}$lymphocytes along with costimulatory factors and instructional signals to activate the lymphocytes becoming MHC-I restricted CTLs. However, in most cases, the virus does not invade mDCs directly but instead infects cells other than mDCs. In such cases, the extrinsic viral antigen and dsRNA can be taken up into mDCs and these mDCs in turn present the antigen epitope with MHC-I molecules to $\mathrm{CD}^{+}$lymphocytes inducing a CTL response. This mechanism is referred to as crosspriming and inducible by TLR3-TRIF signaling and MDA5-MAVS signaling [107, 108]. Type I IFN produced through these signal pathways also enhances the cross-priming ability of mDCs possibly via augmenting their capacity to deliver costimulatory signals [102] or directly stimulation of $\mathrm{CD} 8^{+}$ T-cells [109]. The mechanism of mDCs uptake of the extrinsic antigens involves phagocytosis of particulate antigen, pinocytosis of soluble antigen and receptors mediating crosspresentation such as $\mathrm{Fc}$ receptor, mannose receptor and Dectin-1 [110]. The ability of cell-associated poly (I:C) with antigen to induce robust cross-priming responses in naïve mice is completely lost in the Tlr3-deficient chimera mice [107]. Immunized with protein along with alum and poly (I:C), the expansion of antigen-specific $\mathrm{CD}^{+} \mathrm{T}$-cell can be reduced in both MAVS-deficient and TRIF-deficient mice and entirely abrogated in the bideficient mice [108]. Type I IFN produced through TRIF or MAVS signal pathway also enhances cross-priming by mDCs $[102,109]$. A recent report suggested that $\mathrm{CD} 8^{+}$T-cells can be activated by dsRNA directly triggering TLR3 [111]. Priming of IFN- $\gamma$-producing $\mathrm{CD}^{+}$T-cells by dying tumor cells failed in the absence of a functional IL-1 receptor 1 and in Nlpr3-deficient or caspase1-deficient mice unless exogenous IL-1 was present [112]. This suggests that the NLRP3 inflammasome is involved in the activation of CTLs.

3.4. Activation of Th17 Cells. Th17 cell is a proinflammatory lymphocyte belonging to Th cell subset $[113,114]$. This subset preferentially produces IL-17, IL-17F, IL-22, and IL21, but not IFN- $\gamma$ or IL-4 [115]. Naïve T-cells are induced by transforming growth factor (TGF)- $\beta$ to differentiate into two reciprocal subsets, that is, Th17 cells and Treg cells under different polarizing signals. IL-6 is the polarizing signal of Th17 which switches the transcriptional program initiated by TGF- $\beta$ to induce the development of Th17 cells and blocks the development of Treg cells [116-118]. IL-23 plays a role in amplifying and stabilizing the phenotype of Th17 cells [119]. However, receptors for IL-23 are not expressed in naïve T-cells. In fact, Th17 cells can express such receptors if induced by TGF- $\beta$ acting through ROR- $\gamma$ t which is a unique transcription factor of Th17 (the human counterpart of murine ROR- $\gamma \mathrm{t}$ is ROR-c) [120]. ROR- $\gamma \mathrm{t}$ is the key transcription factor that orchestrates the differentiation of Th17 effector cell lineage by inducing transcription of the IL17 gene in naïve helper T-cells and is also required for the development of IL-17 producing cells in the presence of IL6 and TGF- $\beta$ [121]. IL- 6 is involved in upregulation of IL23R mRNA expression, and IL-6 and IL-23 synergistically augment its protein expression [122]. Therefore, IL-23 acts on T-cells that are already committed to the Th17 lineage rather than inducing Th17 differentiation.

Th17 cells are engaged in the neutrophil related inflammation against infections of fungi and certain extracellular bacteria [115]. Most parenchymal cells express IL-17 receptors that interact with IL-17 that are expressed primarily from Th17 cells to produce proinflammatory factors such as IL-1, IL-6, IL-8, tumor necrosis factor (TNF) and matrix metalloproteinases $[115,123]$. Th17 cells can also induce chemokine production which attracts numerous effector Tcells into inflammatory area promoting the inflammatory response. Thus, inappropriate regulation of Th17 cells activities is associated with chronic inflammation and severe immunopathologic conditions such as autoimmunity [115]. Various studies have suggested that TRIF signal pathway is involved in Th17 response. TRIF signaling in mDCs might induce IL-12 and IL-23 production and play a role in Th17 activation [124]. However, the TLR3 pathway activated by dsRNA induces activation of IRF3 and IRF7 which exclusively induce p35 and p28 but not p19. These in turn would induce IL-12 (p35 and p40) and IL-27 (Epstein-Barr virus-induced gene 3 and p28) but not IL-23 (p19 and p40) [125]. Stimulation of endosomal TLR3 by poly (I:C) can induce $\mathrm{mDCs}$ to produce both IL-12p70 and IL-27; the former promotes Th1 cells to produce IFN- $\gamma$ which can inhibit Th17 cells generation and the latter inhibits Th17 cells differentiation in a STAT1-dependent manner. Thus, poly (I:C) is likely to dampen Th17 responses [126]. TRIFdependent type I IFN production along with its downstream signaling pathway negatively regulates Th17 development and constrains Th17-mediated autoimmune inflammation in mice [127]. It has also been reported that poly (I:C) can induce synthesis of both IL-17 and IL-21 and drive the differentiation of naïve Th cells into an IL-21 but not into an IL-17-producing phenotype without affecting the levels of transcription factors T-bet, GATA-3, or retinoic acid receptor-related orphan receptor C [128]. Thymic stromal lymphopoietin (TSLP) is a hemopoietic cytokine capable of conditioning $\mathrm{mDCs}$ and orientating the differentiation of naïve T-cells towards a Th2 profile. $\mathrm{mDCs}$ activated by a combination of TSLP and poly (I:C) are capable of priming naïve $\mathrm{CD}^{+}{ }^{+}$T-cells to differentiate into Th17-cytokineproducing cells with a central memory T-cell phenotype without changing the Th2 polarization property of TSLP [129].

\section{Potential Application of dsRNA as a Vaccine Adjuvant}

4.1. The Adjuvant Properties of dsRNA. Innate immunity shapes adaptive immunity. Activated immune cells present specific antigen epitope associated with MHCI/II molecules along with costimulatory and instructional signals to naïve T-cells to stimulate activation, differentiation 
and proliferation of immunoreactive T-cells. As a potent activator of both innate and adaptive immunity, dsRNA simultaneously administered with a foreign antigen can act as an immunoadjuvant to induce specific adaptive immunity against the foreign antigen $[91,130]$.

Upon dsRNA stimulation, type I IFN production by DCs is critical for the adjuvant property of poly (I:C) [92]. Type I IFN is considered to be the major player linking innate to adaptive immunity. Besides activating DCs in an autocrine or paracrine manner, type I IFN is capable of inducing an antigen-specific $\mathrm{CD} 8^{+} \mathrm{T}$-cell response, a $\mathrm{CD} 4^{+} \mathrm{Th} 1$ cell response and enhances the primary antibody response [2].

Salaun et al. (2009) demonstrated that proliferation and IFN- $\gamma$ production of antigen-specific $\mathrm{CD}^{+} \mathrm{T}$-cells in the mice immunized by antigen GP33 (an $\mathrm{H}-2 \mathrm{D}^{\mathrm{b}}$ restricted peptide derived from Lymphocytic Choriomeningitis virus glycoprotein 33-41) with poly (I:C) adjuvant is abrogated when this regimen is administered in TLR3 ${ }^{-/-}$mice [131]. The mRNA of TLR3 is undetectable in either $\mathrm{CD} 8^{+}$effector or $\mathrm{CD}^{+}$effector memory T-cells. $\mathrm{CD} 8^{+} \mathrm{T}$-cell proliferation and the ability of INF- $\gamma$ production are not affected by direct stimulation with poly (I:C) and specific TCR. Therefore, it appears that the adjuvant effect of poly (I:C) may be TLR3-dependent without any direct effect on $\mathrm{CD}^{+} \mathrm{T}$ cells [131]. However, Ngoi et al. (2008) experimenting on (C57BL/6) mice that were TLR3 ${ }^{-/-}$and TRIF-deficient, with the poly (I:C) (InvivoGen) but using a different antigen, staphylococcal enterotoxin $\mathrm{A}$, showed that $\mathrm{CD}^{+} \mathrm{T}$-cells expansion was not impaired, that is, a type I IFN production in response to poly (I:C) occurred [132]. Splenocytes from naïve wild-type mice can produce IL-10 in a dose-dependent manner upon stimulation with poly (I:C) in the absence of antigen while IL-10 production was impaired in TLR3 ${ }^{-/-}$ mice. Although these IL-10 producing cells may be innate immune cells, the IL-10 produced acts as a suppressive signal for adaptive immunity. Thus, the presence of TLR3 may suppress the development of adaptive immunity [132]. Indeed, the activation of NK cells, involved in innate immunity, is inducible by poly (I:C) via both MAVS- and TRIF-dependent pathways [133]. Kumar et al. [108] reported that in MAVS-deficient or TRIF-deficient mice immunized with OVA, alum and poly (I:C), the antigen-specific $\mathrm{CD} 8^{+}$ T-cell expansion was reduced in either MAVS-deficient or TRIF-deficient mice and was entirely abrogated in the doubly deficient mice. Hence, the adjuvant effects of poly (I:C) requires a cooperative activation of TLR and cytoplasmic RNA helicase pathways [108]. Contamination of proteins used as antigens in these studies with other TLR ligands [93] or the contamination of $\mathrm{CD}^{+} \mathrm{T}$-cells with other immune cells like innate cells might be a possible explanation of the discrepancy.

With respect to human $\mathrm{CD}^{+}{ }^{+}$T-cells, TLR3 mRNA expression has been detected in human effector and effector memory cells but not in naïve and central memory T-cells [134]. The addition of poly (I:C) significantly increased the quantity of IFN- $\gamma$ released by effector and/or effector memory $\mathrm{CD}^{+} \mathrm{T}$-cells in response to PHA in a dosedependent manner. However, poly (I:C) by itself did not detectably induce IFN- $\gamma$ release by any of the purified $\mathrm{CD}^{+}$
T-cell subsets. Furthermore, the addition of poly (I:C) had no effect on the cytolytic activity of CTL. Therefore, it is likely that the adjuvant effects and the corresponding mechanism of poly (I:C) are different in human and mouse cells.

4.2. dsRNA as Vaccine Adjuvant against Viral Infection. Lau et al. (2009) reported that mice vaccinated with H5N1 influenza vaccine with PIKA (a stabilized dsRNA) as adjuvant experienced a maximum three-fold increase in antibody titer comparable to that produced by mice immunized by vaccine with complete Freund's adjuvant [135]. Vaccination significantly reduced the virus titer in the lung of mice challenged after immunization with the $\mathrm{H} 5$ vaccine and PIKA adjuvant. Without a specific vaccine, sole PIKA administration was also capable of reducing pulmonary viral titer in mice [135]. This immunoprotective property of dsRNA against influenza virus was further demonstrated by other studies using another synthetic dsRNA analogue poly ICLC comprising of poly (I:C) stabilized with L-lysine and carboxymethylcellulose $[136,137]$. PIKA was also able to induce activation and proliferation of B cells and NK cells. When HBsAg was coadministered, an increase in HBsAgspecific IgG production was noted. However, PIKA did not activate $\mathrm{CD}^{+}$and $\mathrm{CD} 8^{+}$T-cells [138]. Nonetheless, most studies suggested that poly (I:C) based dsRNA analogues displayed Th1 adjuvant property capable of activating antigen specific $\mathrm{CD}^{+}$and $\mathrm{CD} 8^{+}$T-cells when administrated as vaccine adjuvant $[92,105,131,132,139,140]$. Another dsRNA analogue, poly (I:C12U) (Ampligen), was effective in inducing mDCs maturation and promoted Th1 cytokine IL-12 production while significantly decreased suppressive cytokine IL-10 production compared to that induced by poly (I:C) in healthy donors [140]. Intranasal administration of an Ampligen adjuvanted H5N1 vaccine resulted in the secretion of vaccine-specific IgA and IgG in nasal mucosa and serum respectively and protected mice against homologous and heterologous viral challenge [141]. Immunization of mice by hepatitis $C$ virus nonstructural protein 3 and poly (I:C) emulsified with Montanide ISA 720 have demonstrated that the protein-based vaccine adjuvant, poly (I:C) was capable of eliciting Th1-biased adaptive immunity although the protein-based vaccine alone favors Th2-polarization. Additionally, the adjuvant potency of poly (I:C) emulsified with Montanide ISA 720 was much stronger than that of dispersed delivered poly (I:C) which suggests that protection of poly (I:C) from rapid degradation by ribonucleases was crucial for the adjuvant property of poly (I:C) [105]. Other groups have also suggested an Th1 adjuvant role of poly (I:C) $[92,139]$. More importantly, induction of $\mathrm{CD}^{+} \mathrm{Th}$ cells by poly (I:C) is required for memory in $\mathrm{CD}^{+} \mathrm{T}$ lymphocytes [142]. $\mathrm{CD}^{+}$CTL memory play important roles in vaccine design for prevention of viral infection. Therefore, it seems that the adjuvant property of distinct dsRNA molecules may be different as suggested by Avril et al. [96].

Several synthetic dsRNA analogues are commercially available such as poly (I:C), poly (I:C12U), poly ICLC, poly (A:U) and PIKA. Poly (I:C) is a mismatched dsRNA with one 
strand being a polymer of inosinic acid, the other a polymer of cytidylic acid. It was discovered in 1967 by Hilleman's group [143] who also discovered IFN induction by dsRNA [144] before the discovery of its molecular receptors of TLR3 [145] and MDA-5 [56, 146]. However, toxicity concerns prevent the clinical utility of poly (I:C) [147-149]. Thus, most studies using poly (I:C) as an immunoprotective or vaccine adjuvant have been undertaken in animals. Attempts to design dsRNA analogues that can induce IFN with less toxicity have resulted in poly $(\mathrm{I}: \mathrm{C} 13 \mathrm{U})$ being modified to poly (I:C12U) [150]. Poly (I:C12U) differs from poly (I:C) in that every 13th cytosine of the dsRNA, cytosine $(\mathrm{C})$ is replaced by uracil (U). Uracil is unable to bond hydrogen to the hypoxanthine of the partner poly (I) strand and therefore results in a mismatched base which would be more readily degraded than the parent molecule [147]. This poly (I:C) analogue has been applied in clinical trials for chronic fatigue syndrome and AIDS. It was generally well-tolerated via intravenous administration with insomnia and dry skin the most commonly reported adverse events [151]. It also exhibited profound and uniformly suppressive effects on HIV expression in vivo [152]. Poly ICLC was introduced by Levy et al. in 1975 and comprised of poly (I:C) with polyL-lysine and carboxymethylcellulose [153]. This complex is $5-10$ times as resistant to hydrolysis by primate serum as the parent poly ( $\mathrm{I}: \mathrm{C})$ and has a thermal denaturation temperature about $40^{\circ} \mathrm{C}$ higher than that of poly (I:C). It was able to induce significant levels of serum IFN in monkey and chimpanzee under conditions in which poly (I:C) itself induced no IFN [153]. In an early clinical trial in patients with malignancy, toxic reactions composed of fever, nausea, hypotension, thrombocytopenia and leukopenia, erythema, polyarthralgia with myalgia [154]. PIKA is a stabilized dsRNA greater than 100 base pairs in length [135]. Clinical information regarding PIKA is limited and the available data are only from animals $[135,138,155]$. Stahl-Hennig et al. (2009) reported that poly (I:C) and its analogues poly ICLC and poly (I:C12U) are effective adjuvants for the induction of protein-specific cellular immune responses [104]. Among the three molecular analogues, poly ICLC was the most potent adjuvant in monkeys. This may be attributed to poly ICLC being more stable against primate serum nucleases. Another study using HIV gag as antigen showed that both poly (I:C) and poly ICLC were able to induce antigen-specific $\mathrm{CD}^{+}{ }^{+}$T-cell response without IL-4 and IL-17 secretion, confirming Th1-polarized adjuvanticity. This adjuvant role is type I IFN-mediated [92]. Gowen et al. [156] revealed that poly (I:C) treatment significantly protected TLR3 ${ }^{-/-}$ mice from the lethal Punta Toro virus infection despite deficiencies in cytokine induction while poly (I:C12U) was unable to protect $\mathrm{TLR}^{-/-}$mice from lethal challenge. It failed to produce IFN- $\alpha$, IFN- $\beta$, and IL- 6 . However, in wildtype mice, poly (I:C12U) treatment was able to promote IFN- $\alpha$, IFN- $\beta$, and IL- 6 production and conferred protection from Punta Toro infection [156]. These results suggested that both TLR3 and MDA-5 are required for poly (I:C) to elicit immune responses but poly (I:C12U) requires only TLR3. This conclusion was verified later by Trumpfheller et al. (2008) [139]. Distinct forms of poly (I:C) with different molecular weights or poly (I:C12U) are not equivalent in their biological behavior [96].

4.3. dsRNA as Vaccine Adjuvant against Cancer. DCs and macrophages are major sensor cells to invading pathogen and transformed cells via germ-line encoded PRRs. Upon sensing pathogens or tumor cells, activation involves these cells becoming APCs triggering innate immunity and thereby shaping adaptive immunity through cross-priming to eliminate the invading microbes and tumor cells. Cancer cells are malignantly transformed cells of the host and are capable of expressing antigens that are not expressed or in trace amount in healthy host and are referred to as tumor associated antigens (TAAs) [157]. Adaptive immunity is the major mechanism to eliminate cancer cells in the late stage of host defense responses by the generation of tumor-specific immunity [158]. Various reports have demonstrated that the recruitment of tumor infiltrating lymphocytes, especially $\mathrm{CD}^{+}$T-cells, is closely related to prognosis of the patients [159-161]. However, the anticancer immunity of the tumorbearing host is usually weak or anergic due to either the weak antigenicity of TAAs or because of suppressive immunity in the host. Thus, enhancing the immune response, in particular TAA-specific CTL response and overcoming the immune suppression is crucial for anticancer immunity. Indeed, Provenge (also known as sipuleucel-T or APC8015) (Dendreon, Seattle, WA), a new cancer vaccine for advanced prostate cancer, was recently approved by FDA at April 29, 2010 [162]. Provenge works by ex vivo stimulation of isolated autogenous DCs of the patient with a fusion protein of full-length human prostatic acid phosphatase (PAP) and granulocyte-macrophage colony stimulating factor. This stimulation of DCs results in activation of APCs. The PAP activated APCs are suspended in lactated Ringer's solution, after removing the excessive antigen, and then infused into the patient resulting in innate and adaptive immunity against cancer cells [163]. Clinical trials have shown statistically significant prolonged median survival times [163-165]. This is the first FDA approved therapeutic tumor vaccine [166].

TLRs have been involved in the immunotherapy for cancer. Agonists of TLRs with the capacity of priming and shaping adaptive immunity have aroused significant interest in the development of cancer immunotherapy, in particular imiquimod, unmethylated cytosine preceding guanosine motif oligodeoxynucleotides (CpG ODNs), and dsRNA which act as agonistically with TLR7, TLR9, and TLR3, respectively [167].

Activation of TLR3 by dsRNA was capable of inducing either anticancer immune response or cancer cells apoptosis via TLR3 receptor expressed on a variety of cancer cells [168-173]. The two mechanisms of dsRNA against cancer work synergistically. Apoptosis of cancer cells presents the immune system with a new repertoire of TAAs in a TLR3 activation context that is favorable to the development of long-term anticancer immune responses. Poly (I:C12U) is capable of inducing phenotypic and functional maturation of DCs generated from peripheral blood monocytes of advanced ovarian cancer patients with sustained bioactive 
IL-12p70 production. DCs primed with tumor lysate and matured with poly (I:C12U) are capable of generating Th1biased specific anticancer responses in peripheral blood T-cells derived from cancer patients in the presence of ascites medium containing immunosuppressive cytokines. Using ovarian cancer ascites as an in vitro model, $\mathrm{CD} 8^{+} \mathrm{T}$ cells derived from ascites fluid primed with tumor antigen loaded DCs matured with poly (I:C12U), exhibited cytotoxic activity with the capacity of lysis of autologous tumor cells $[140,174]$. Another synthetic poly (I:C) derivative, poly ICLC, more effective as an type I IFN inducer in humans but also associated with more clinical side-effects [175], has been involved in a variety of clinical trials of malignancy treatment in the last 30 years [176-180]. When poly ICLC was used either in monotherapy or in combination therapy, it exhibited immunomodulatory effects [181] and enhancement of IL-2-induced NK lytic activity in cancer patients [179]. However, sole poly ICLC administration did not improve the survival of cancer patients $[177,179,180]$. Despite the unfavorable results of poly ICLC in tumor therapy, auspicious results were noted when used as a cancer vaccine adjuvant in mice [182]. When poly ICLC was administered with tumor antigen-derived peptide epitopes as a cancer vaccine adjuvant in a murine brain tumor model, it was capable of enhancing antigen-specific CTL response. This facilitates the infiltration of antigen-specific T-cells into the tumor site, promotes tumor homing of antigen-specific T-cells and improves the survival of tumorbearing mice by inducing long term antitumor protection [182]. A phase I/II clinical trial using type I polarizing DCs loaded with peptides in combination with poly ICLC in patients with recurrent malignant glioma is currently being conducted [183]. Polyadenylic polyuridylic acid [poly (A:U)] is another type of synthetic dsRNA analogue that has been used in combination with chemotherapy for locally advanced gastric cancer after curative surgery patients compared with chemotherapy alone [184] despite of its inefficiency as a single adjuvant [185]. A prolonged overall and recurrencefree survival was noted. Poly (A:U) is capable of inducing Th1 cell generation and antibody production in mice when coadministered with protein [186]. In vivo targeted delivery of tumor associated epitope to APCs in conjunction with poly (A:U) resulted in correction of the ineffective response to idiotypic epitopes, control of tumor growth, establishment of immune memory and protection against tumors bearing antigenic variants [187]. The immunoadjuvant effects of poly (A:U) is believed to signal TLR3 and TLR7 [188].

TLR3 agonists may be an double-edged sword in cancer treatment [189]. TLR3 expresses not only on immune cells sensing dsRNA and triggering immune response but also on tumor cells exhibiting other functions [190]. It is well known that viral infection is closely related with carcinogenesis and approximately $20 \%$ of all cancers are associated with infectious agents [191] such as human papillomavirus [191] and hepatitis viruses [192]. Prevention of viral infection is able to significantly reduce the occurrence rate of cancer [193-195]. Inhibition of virus replication reduced the development of cancer dramatically even in chronically viral infected patients $[194,196]$. In this scenario, it is suspected that dsRNA, as intermediate of viral replication, is involved in the carcinogenesis. Long before the discovery of TLR3, researchers have found that dsRNA, such as poly (A:U) treatment is capable of enhancing carcinogenesis in animals $[197,198]$. Studies have suspected that activation of TLRs in cancer cells could promote tumor progression and chemoresistance by activation of NF- $\kappa$ B to induce upregulation of antiapoptotic proteins and to inhibit proapoptotic proteins [190]. Consistently, several groups have reported that TLR agonists stimulate the proliferation and suppressor function of Treg cells and so attenuate the antitumor effects $[199,200]$. However, most studies were conducted by activation of the TLRs other than TLR3 [190, 201, 202]. Recent reports suggested that TLR3 expression is much higher in metastatic cancer cells in comparison with primary cancer cells [169]. In human hepatocellular carcinoma cells, TLR3 can be expressed both on cell surface and in cytosol and only activation of the cytoplasmic TLR3 can induce cancer apoptosis accompanied by the downregulation of antiapoptotic protein [171]. In situ stimulation of TLR3 and synergistic molecule CD40 can transform ovarian cancer-infiltrating DCs from immunosuppressive to immunostimulatory cells thus exhibiting therapeutic potential of TLR3 activation [203]. Activation of TLR3 in nasopharyngeal carcinoma cells can inhibit cell migration by downregulation of chemokine receptor CXCR4 suggesting antimetastasis activity of endogenous human TLR3 expression in cancer cells [204]. Thus, it seems that activation of endogenous human TLR3 expressed by cancerous cells may induce direct pro-apoptotic activity of the tumor cells [168]. Additionally, mRNA escaping from damaged tissue or contained within endocytosed cells could serve as an endogenous ligand for TLR3 [205].

\section{Perspectives}

Double-stranded RNA and its synthetic analogues, such as poly (I:C) and poly (A:U) have long been known to be potent type I IFN inducers and immunomodulators [144]. However, the fact TLR3 recognized dsRNA and activates NF- $\kappa$ B signal pathway was only discovered in 2001 [145]. Subsequently, other dsRNA receptors, RIG-I/MDA-5 and NLRP3 have been uncovered $[7,75,206]$. Studies of the interaction of dsRNA and its receptors have focused on immune cells. It is unknown if there are any endogenous ligands that share these receptors with exogenous dsRNA. Additionally, dsRNA receptors especially TLR3 are found expressed ubiquitously in the body. It is reasonable that not all types of cells are involved in sensing viral infection and eliciting immune response. Thus, the role of these receptors in other type of cells deserves further exploration.

dsRNA is able to induce both innate and adaptive immunity to eliminate the invading virus. However, the virus may evolve protective mechanism that enables it to destroy the dsRNA-induced signaling thereby protecting itself by evasion from the immune response of the host [207, 208]. Thus, overcoming viral protective mechanism(s) is desirable.

There is insufficient information regarding TLR3 activation in cancerous cells. Recent report suggested that 
poly (I:C) binds to endo/lysosomal MDA-5 and activates apoptotic caspases in melanoma cells to induce their self degradation by autophagy and apoptosis [209]. The possibility that other dsRNA receptors may be present in tumor cells deserves further investigation. Having such knowledge would be very helpful for development of therapeutic tumor vaccine with dsRNA analogue adjuvant. In addition, the effects of dsRNA signaling on Treg cell are not known. It appears that there needs to be a balancing act between the possible carcinogenesis and the immune stimulating property of dsRNA when dsRNA analogues are considered as immunoadjuvants in tumor immunotherapy.

Although dsRNA have displayed favorable immunostimulatory and protective properties, many questions remain to be answered. Further investigations to uncover its roles in viral infection, carcinogenesis or anticancer actions deserve consideration.

\section{Abbreviations}

AP-1: $\quad$ activating protein 1

ASC: apoptosis-associated speck-like protein containing a caspase-activating and recruitment domain

CARD: caspase recruitment domain

dsRNA: double-stranded RNA

FADD: Fas-associated cell death domain

IFN: interferon

IKK: $\quad$ I $\kappa$ B kinase-related kinase

IL: interleukin

IRF: interferon regulatory factor

LRR: leucine-rich repeat

MAVS: mitochondrial antiviral signaling adapter

MDA-5: melanoma differentiation-associated gene 5

NACHT: (NAIP, CIITA, HET-E, TP-1) domain

NAIP: Neuronal apoptosis inhibitory protein

CIITA: Class II transactivator

HET-E: plant Het product involved in vegetative incompatibility

TP-1: $\quad$ Telomerase-associated protein 1

NAP1: nuclear factor- $\kappa$ B activating kinase-associated protein 1

NEMO: nuclear factor $-\kappa \mathrm{B}$ essential modulator

$\mathrm{NF}-\kappa \mathrm{B}:$ nuclear factor $-\kappa \mathrm{B}$

NLRP3: nucleotide-binding domain and leucine-rich repeat containing gene family pyrin domain 3

PI3K: phosphatidylinositol 3-kinase

PRR: proline-rich region

PYD: $\quad$ pyrin domain

RIP1: receptor-interacting protein 1

TAB: $\quad$ transforming growth factor $\beta$-activating kinase binding protein

TAK: $\quad$ transforming growth factor $\beta$-activating kinase

TANK: TRAF family member-associated NF- $\kappa$ B activator

TBK1: TRAF family member-associated NF- $\kappa$ B activator-binding kinase 1

TIR: Toll/IL-1 receptor domain

TLR3: Toll-like receptor 3
TRADD: tumor necrosis factor receptor-associated death domain

TRAF6: tumor necrosis factor receptor-associated factor 6

TRIF: Toll/IL-1 receptor domain-containing adaptor inducing IFN- $\beta$.

\section{Acknowledgment}

The authors thank Dr. J. W. Shih, Ph.D. from the National Institute of Diagnostics and Vaccine Development in Infectious Diseases, Xiamen University, China, for his advices and substantial help in the preparation of this paper.

\section{References}

[1] T. Seya, M. Matsumoto, T. Ebihara, and H. Oshiumi, "Functional evolution of the TICAM-1 pathway for extrinsic RNA sensing," Immunological Reviews, vol. 227, no. 1, pp. 4453, 2009.

[2] H. J. Warshakoon, J. D. Hood, and M. R. Kimbrell et al., "Potential adjuvantic properties of innate immune stimuli," Human Vaccines, vol. 5, no. 6, pp. 381-394, 2009.

[3] K. J. Ish II, S. Koyama, A. Nakagawa, C. Coban, and S. Akira, "Host innate immune receptors and beyond: making sense of microbial infections," Cell Host and Microbe, vol. 3, no. 6, pp. 352-363, 2008.

[4] H. Kumar, T. Kawai, and S. Akira, "Pathogen recognition in the innate immune response," Biochemical Journal, vol. 420, no. 1, pp. 1-16, 2009.

[5] S. Bauer, T. Müller, and S. Hamm, "Pattern recognition by Toll-like receptors," Advances in Experimental Medicine and Biology, vol. 653, pp. 15-34, 2009.

[6] R. Medzhitov, P. Preston-Hurlburt, and C. A. Janeway Jr., "A human homologue of the Drosophila toll protein signals activation of adaptive immunity," Nature, vol. 388, no. 6640, pp. 394-397, 1997.

[7] M. Yoneyama, M. Kikuchi, and T. Natsukawa et al., "The RNA helicase RIG-I has an essential function in doublestranded RNA-induced innate antiviral responses," Nature Immunology, vol. 5, no. 7, pp. 730-737, 2004.

[8] M. Yoneyama and T. Fujita, "Function of RIG-I-like receptors in antiviral innate immunity," Journal of Biological Chemistry, vol. 282, no. 21, pp. 15315-15318, 2007.

[9] J. H. Fritz, R. L. Ferrero, D. J. Philpott, and S. E. Girardin, "Nod-like proteins in immunity, inflammation and disease," Nature Immunology, vol. 7, no. 12, pp. 1250-1257, 2006.

[10] J. P.-Y. Ting, S. B. Willingham, and D. T. Bergstralh, "NLRs at the intersection of cell death and immunity," Nature Reviews Immunology, vol. 8, no. 5, pp. 372-379, 2008.

[11] H. Kumar, T. Kawai, and S. Akira, "Toll-like receptors and innate immunity," Biochemical and Biophysical Research Communications, vol. 388, no. 4, pp. 621-625, 2009.

[12] P. Ranjan, J. B. Bowzard, J. W. Schwerzmann, V. Jeisy-Scott, T. Fujita, and S. Sambhara, "Cytoplasmic nucleic acid sensors in antiviral immunity," Trends in Molecular Medicine, vol. 15, no. 8, pp. 359-368, 2009.

[13] X. Li, C. Lu, and M. Stewart et al., "Structural basis of doublestranded RNA recognition by the RIG-I like receptor MDA5," Archives of Biochemistry and Biophysics, vol. 488, no. 1, pp. 23-33, 2009. 
[14] L. Franchi, T. Eigenbrod, R. Muñoz-Planillo, and G. Nuñez, "The inflammasome: a caspase-1-activation platform that regulates immune responses and disease pathogenesis," Nature Immunology, vol. 10, no. 3, pp. 241-247, 2009.

[15] T. Kawai and S. Akira, "Innate immune recognition of viral infection," Nature Immunology, vol. 7, no. 2, pp. 131-137, 2006.

[16] M. S. Jin and J.-O. Lee, "Structures of TLR-ligand complexes," Current Opinion in Immunology, vol. 20, no. 4, pp. 414-419, 2008.

[17] M. S. Jin and J.-O. Lee, "Structures of the toll-like receptor family and its ligand complexes," Immunity, vol. 29, no. 2, pp. 182-191, 2008.

[18] N. Matsushima, T. Tanaka, and P. Enkhbayar et al., "Comparative sequence analysis of leucine-rich repeats (LRRs) within vertebrate toll-like receptors," BMC Genomics, vol. 8, article 124, 2007.

[19] J. Bella, K. L. Hindle, P. A. McEwan, and S. C. Lovell, "The leucine-rich repeat structure," Cellular and Molecular Life Sciences, vol. 65, no. 15, pp. 2307-2333, 2008.

[20] J. Choe, M. S. Kelker, and I. A. Wilson, "Crystal structure of human toll-like receptor 3 (TLR3) ectodomain,” Science, vol. 309, no. 5734, pp. 581-585, 2005.

[21] J. K. Bell, J. Askins, P. R. Hall, D. R. Davies, and D. M. Segal, "The dsRNA binding site of human Toll-like receptor 3," Proceedings of the National Academy of Sciences of the United States of America, vol. 103, no. 23, pp. 8792-8797, 2006.

[22] L. Liu, I. Botos, and Y. Wang et al., "Structural basis of tolllike receptor 3 signaling with double-stranded RNA," Science, vol. 320, no. 5874, pp. 379-381, 2008.

[23] J. N. Leonard, R. Ghirlando, and J. Askins et al., "The TLR3 signaling complex forms by cooperative receptor dimerization," Proceedings of the National Academy of Sciences of the United States of America, vol. 105, no. 1, pp. 258-263, 2008.

[24] K. Fukuda, T. Watanabe, and T. Tokisue et al., "Modulation of double-stranded RNA recognition by the N-terminal histidine-rich region of the human toll-like receptor 3," Journal of Biological Chemistry, vol. 283, no. 33, pp. 2278722794, 2008

[25] E. Vercammen, J. Staal, and R. Beyaert, "Sensing of viral infection and activation of innate immunity by toll-like receptor 3," Clinical Microbiology Reviews, vol. 21, no. 1, pp. 13-25, 2008.

[26] H. Oshiumi, M. Matsumoto, K. Funami, T. Akazawa, and T. Seya, "TICAM-1, an adaptor molecule that participates in Toll-like receptor 3-mediated interferon- $\beta$ induction," Nature Immunology, vol. 4, no. 2, pp. 161-167, 2003.

[27] G. C. Sen and S. N. Sarkar, "Transcriptional signaling by double-stranded RNA: role of TLR3," Cytokine and Growth Factor Reviews, vol. 16, no. 1, pp. 1-14, 2005.

[28] M. Matsumoto, K. Funami, and M. Tanabe et al., "Subcellular localization of toll-like receptor 3 in human dendritic cells," Journal of Immunology, vol. 171, no. 6, pp. 3154-3162, 2003.

[29] M. Matsumoto, S. Kikkawa, M. Kohase, K. Miyake, and T. Seya, "Establishment of a monoclonal antibody against human Toll-like receptor 3 that blocks doublestranded RNA-mediated signaling," Biochemical and Biophysical Research Communications, vol. 293, no. 5, pp. 1364-1369, 2002.

[30] H.-K. Lee, S. Dunzendorfer, K. Soldau, and P. S. Tobias, "Double-stranded RNA-mediated TLR3 activation is enhanced by CD14," Immunity, vol. 24, no. 2, pp. 153-163, 2006.
[31] S. Sato, M. Sugiyama, and M. Yamamoto et al., "Toll/IL-1 receptor domain-containing adaptor inducing IFN- $\beta$ (TRIF) associates with TNF receptor-associated factor 6 and TANKbinding kinase 1, and activates two distinct transcription factors, NF- $\kappa \mathrm{B}$ and IFN-regulatory factor-3, in the toll-like receptor signaling," Journal of Immunology, vol. 171, no. 8, pp. 4304-4310, 2003.

[32] M. Matsumoto and T. Seya, "TLR3: interferon induction by double-stranded RNA including poly(I:C)," Advanced Drug Delivery Reviews, vol. 60, no. 7, pp. 805-812, 2008.

[33] N. Cusson-Hermance, S. Khurana, T. H. Lee, K. A. Fitzgerald, and M. A. Kelliher, "Rip1 mediates the trif-dependent Tolllike receptor 3 - and 4 -induced NF- $\kappa \mathrm{B}$ activation but does not contribute to interferon regulatory factor 3 activation," Journal of Biological Chemistry, vol. 280, no. 44, pp. 3656036566, 2005.

[34] M. Sasai, H. Oshiumi, and M. Matsumoto et al., "Cutting edge: NF- $\kappa$ B-activating kinase-associated protein 1 participates in TLR3/Toll-IL-1 homology domain-containing adapter molecule-1-mediated IFN regulatory factor 3 activation," Journal of Immunology, vol. 174, no. 1, pp. 27-30, 2005.

[35] H. Häcker, V. Redecke, and B. Blagoev et al., "Specificity in Toll-like receptor signalling through distinct effector functions of TRAF3 and TRAF6," Nature, vol. 439, no. 7073, pp. 204-207, 2006.

[36] S. N. Sarkar, K. L. Peters, C. P. Elco, S. Sakamoto, S. Pal, and G. C. Sen, "Novel roles of TLR3 tyrosine phosphorylation and PI3 kinase in double-stranded RNA signaling," Nature Structural and Molecular Biology, vol. 11, no. 11, pp. 10601067, 2004.

[37] S. N. Sarkar, C. P. Elco, K. L. Peters, S. Chattopadhyay, and G. C. Sen, "Two tyrosine residues of toll-like receptor 3 trigger different steps of NF- $\kappa \mathrm{B}$ activation," Journal of Biological Chemistry, vol. 282, no. 6, pp. 3423-3427, 2007.

[38] I. B. Johnsen, T. T. Nguyen, and M. Ringdal et al., "Toll-like receptor 3 associates with c-Src tyrosine kinase on endosomes to initiate antiviral signaling," EMBO Journal, vol. 25, no. 14, pp. 3335-3346, 2006.

[39] W. J. Kaiser and M. K. Offermann, "Apoptosis induced by the toll-like receptor adaptor TRIF is dependent on its receptor interacting protein homotypic interaction motif," Journal of Immunology, vol. 174, no. 8, pp. 4942-4952, 2005.

[40] O. Takeuchi and S. Akira, "MDA5/RIG-I and virus recognition," Current Opinion in Immunology, vol. 20, no. 1, pp. 1722, 2008.

[41] L. Unterholzner and A. G. Bowie, "The interplay between viruses and innate immune signaling: recent insights and therapeutic opportunities," Biochemical Pharmacology, vol. 75, no. 3, pp. 589-602, 2008.

[42] T. Saito, R. Hirai, and Y.-M. Loo et al., "Regulation of innate antiviral defenses through a shared repressor domain in RIG1 and LGP2," Proceedings of the National Academy of Sciences of the United States of America, vol. 104, no. 2, pp. 582-587, 2007.

[43] A. Baum and A. Garcia-Sastre, "Induction of type I interferon by RNA viruses: cellular receptors and their substrates," Amino Acids, vol. 38, no. 5, pp. 1283-1299, 2010.

[44] S. Cui, K. Eisenächer, and A. Kirchhofer et al., "The Cterminal regulatory domain is the RNA $5^{\prime}$-triphosphate sensor of RIG-I," Molecular Cell, vol. 29, no. 2, pp. 169-179, 2008.

[45] K. Takahasi, H. Kumeta, and N. Tsuduki et al., "Solution structures of cytosolic RNA sensor MDA5 and LGP2 Cterminal domains: identification of the RNA recognition 
loop in RIG-I-like receptors," Journal of Biological Chemistry, vol. 284, no. 26, pp. 17465-17474, 2009.

[46] D. A. Pippig, J. C. Hellmuth, and S. Cui et al., "The regulatory domain of the RIG-I family ATPase LGP2 senses doublestranded RNA," Nucleic Acids Research, vol. 37, no. 6, pp. 2014-2025, 2009.

[47] S. Myong, S. Cui, and P. V. Cornish et al., "Cytosolic viral sensor RIG-I is a $5^{\prime}$-triphosphate-dependent translocase on double-stranded RNA," Science, vol. 323, no. 5917, pp. 10701074, 2009.

[48] D. Bamming and C. M. Horvath, "Regulation of signal transduction by enzymatically inactive antiviral RNA helicase proteins MDA5, RIG-I, and LGP2," Journal of Biological Chemistry, vol. 284, no. 15, pp. 9700-9712, 2009.

[49] A. Schmidt, T. Schwerd, and W. Hamm et al., " 5 'triphosphate RNA requires base-paired structures to activate antiviral signaling via RIG-I," Proceedings of the National Academy of Sciences of the United States of America, vol. 106, no. 29, pp. 12067-12072, 2009.

[50] M. Yoneyama, M. Kikuchi, and K. Matsumoto et al., "Shared and unique functions of the $\mathrm{DExD} / \mathrm{H}$-box helicases RIG-I, MDA5, and LGP2 in antiviral innate immunity," Journal of Immunology, vol. 175, no. 5, pp. 2851-2858, 2005.

[51] F. Diao, S. Li, and Y. Tian et al., "Negative regulation of MDA5- but not RIG-I-mediated innate antiviral signaling by the dihydroxyacetone kinase," Proceedings of the National Academy of Sciences of the United States of America, vol. 104, no. 28, pp. 11706-11711, 2007.

[52] V. Hornung, J. Ellegast, and S. Kim et al., " 5 '-triphosphate RNA is the ligand for RIG-I," Science, vol. 314, no. 5801, pp. 994-997, 2006.

[53] A. Pichlmair, O. Schulz, and C. P. Tan et al., "RIG-Imediated antiviral responses to single-stranded RNA bearing 5'-phosphates," Science, vol. 314, no. 5801, pp. 997-1001, 2006.

[54] H. Kato, O. Takeuchi, and E. Mikamo-Satoh et al., "Length-dependent recognition of double-stranded ribonucleic acids by retinoic acid-inducible gene-I and melanoma differentiation-associated gene 5," Journal of Experimental Medicine, vol. 205, no. 7, pp. 1601-1610, 2008.

[55] M. Schlee, E. Hartmann, and C. Coch et al., "Approaching the RNA ligand for RIG-I?” Immunological Reviews, vol. 227, no. 1, pp. 66-74, 2009.

[56] L. Gitlin, W. Barchet, and S. Gilfillan et al., "Essential role of mda-5 in type I IFN responses to polyriboinosinic: polyribocytidylic acid and encephalomyocarditis picornavirus," Proceedings of the National Academy of Sciences of the United States of America, vol. 103, no. 22, pp. 8459-8464, 2006.

[57] R. B. Seth, L. Sun, C.-K. Ea, and Z. J. Chen, "Identification and characterization of MAVS, a mitochondrial antiviral signaling protein that activates NF- $\kappa \mathrm{B}$ and IRF3," Cell, vol. 122, no. 5, pp. 669-682, 2005.

[58] S. K. Saha, E. M. Pietras, and J. Q. He et al., "Regulation of antiviral responses by a direct and specific interaction between TRAF3 and Cardif," EMBO Journal, vol. 25, no. 14, pp. 3257-3263, 2006.

[59] M. Baril, M.-E. Racine, F. Penin, and D. Lamarre, "MAVS dimer is a crucial signaling component of innate immunity and the target of hepatitis C virus NS3/4A protease," Journal of Virology, vol. 83, no. 3, pp. 1299-1311, 2009.

[60] E. D. Tang and C.-Y. Wang, "MAVS self-association mediates antiviral innate immune signaling," Journal of Virology, vol. 83, no. 8, pp. 3420-3428, 2009.
[61] M. Yoneyama and T. Fujita, "RNA recognition and signal transduction by RIG-I-like receptors," Immunological Reviews, vol. 227, no. 1, pp. 54-65, 2009.

[62] P. Nakhaei, P. Genin, A. Civas, and J. Hiscott, "RIG-I-like receptors: sensing and responding to RNA virus infection," Seminars in Immunology, vol. 21, no. 4, pp. 215-222, 2009.

[63] L.-G. Xu, Y.-Y. Wang, K.-J. Han, L.-Y. Li, Z. Zhai, and H.-B. $\mathrm{Shu}$, "VISA is an adapter protein required for virus-triggered IFN- $\beta$ signaling," Molecular Cell, vol. 19, no. 6, pp. 727-740, 2005.

[64] R. Yoshida, G. Takaesu, and H. Yoshida et al., "TRAF6 and MEKK1 play a pivotal role in the RIG-I-like helicase antiviral pathway," Journal of Biological Chemistry, vol. 283, no. 52, pp. 36211-36220, 2008.

[65] S. S. Mikkelsen, S. B. Jensen, and S. Chiliveru et al., "RIGI-mediated activation of p38 MAPK is essential for viral induction of interferon and activation of dendritic cells: dependence on TRAF2 and TAK1," Journal of Biological Chemistry, vol. 284, no. 16, pp. 10774-10782, 2009.

[66] M.-C. Michallet, E. Meylan, and M. A. Ermolaeva et al., "TRADD protein is an essential component of the RIG-like helicase antiviral pathway," Immunity, vol. 28, no. 5, pp. 651$661,2008$.

[67] B. Zhong, Y. Yang, and S. Li et al., "The adaptor protein MITA links virus-sensing receptors to IRF3 transcription factor activation," Immunity, vol. 29, no. 4, pp. 538-550, 2008.

[68] H. Ishikawa and G. N. Barber, "STING is an endoplasmic reticulum adaptor that facilitates innate immune signalling," Nature, vol. 455, no. 7213, pp. 674-678, 2008.

[69] L. Jin, P. M. Waterman, K. R. Jonscher, C. M. Short, N. A. Reisdorph, and J. C. Cambier, "MPYS, a novel membrane tetraspanner, is associated with major histocompatibility complex class II and mediates transduction of apoptotic signals," Molecular and Cellular Biology, vol. 28, no. 16, pp. 5014-5026, 2008.

[70] H. Poeck, M. Bscheider, and O. Gross et al., "Recognition of RNA virus by RIG-I results in activation of CARD9 and inflammasome signaling for interleukin $1 \beta$ production," Nature Immunology, vol. 11, no. 1, pp. 63-69, 2010.

[71] F. Martinon, A. Mayor, and J. Tschopp, "The inflammasomes: guardians of the body," Annual Review of Immunology, vol. 27, pp. 229-265, 2009.

[72] L. Franchi, N. Warner, K. Viani, and G. Nuñez, "Function of Nod-like receptors in microbial recognition and host defense," Immunological Reviews, vol. 227, no. 1, pp. 106-128, 2009.

[73] D. D. Leipe, E. V. Koonin, and L. Aravind, "STAND, a class of P-loop NTPases including animal and plant regulators of programmed cell death: multiple, complex domain architectures, unusual phyletic patterns, and evolution by horizontal gene transfer," Journal of Molecular Biology, vol. 343, no. 1, pp. 1-28, 2004.

[74] J. P.-Y. Ting, R. C. Lovering, and E. S. Alnemri et al., "The NLR gene family: a standard nomenclature," Immunity, vol. 28, no. 3, pp. 285-287, 2008.

[75] T.-D. Kanneganti, M. Body-Malapel, and A. Amer et al., "Critical role for Cryopyrin/Nalp3 in activation of caspase1 in response to viral infection and double-stranded RNA," Journal of Biological Chemistry, vol. 281, no. 48, pp. 3656036568, 2006.

[76] T.-D. Kanneganti, N. Özören, and M. Body-Malapel et al., "Bacterial RNA and small antiviral compounds activate caspase-1 through cryopyrin/Nalp3," Nature, vol. 440, no. 7081, pp. 233-236, 2006. 
[77] I. C. Allen, M. A. Scull, and C. B. Moore et al., "The NLRP3 inflammasome mediates in vivo innate immunity to influenza a virus through recognition of viral RNA," Immunity, vol. 30, no. 4, pp. 556-565, 2009.

[78] P. G. Thomas, P. Dash, and J. R. Aldridge Jr. et al., "The Intracellular Sensor NLRP3 Mediates Key Innate and Healing Responses to Influenza A Virus via the Regulation of Caspase-1," Immunity, vol. 30, no. 4, pp. 566-575, 2009.

[79] D. A. Muruve, V. Pétrilli, and A. K. Zaiss et al., "The inflammasome recognizes cytosolic microbial and host DNA and triggers an innate immune response," Nature, vol. 452, no. 7183, pp. 103-107, 2008.

[80] J. H. Pedra, S. L. Cassel, and F. S. Sutterwala, "Sensing pathogens and danger signals by the inflammasome," Current Opinion in Immunology, vol. 21, no. 1, pp. 10-16, 2009.

[81] S. L. Cassel, S. Joly, and F. S. Sutterwala, "The NLRP3 inflammasome: a sensor of immune danger signals," Seminars in Immunology, vol. 21, no. 4, pp. 194-198, 2009.

[82] L. Agostini, F. Martinon, K. Burns, M. F. McDermott, P. N. Hawkins, and J. Tschopp, "NALP3 forms an IL-1 $\beta$ processing inflammasome with increased activity in MuckleWells autoinflammatory disorder," Immunity, vol. 20, no. 3, pp. 319-325, 2004.

[83] M. Razmara, S. M. Srinivasula, and L. Wang et al., "CARD-8 protein, a new CARD family member that regulates caspase1 activation and apoptosis," Journal of Biological Chemistry, vol. 277, no. 16, pp. 13952-13958, 2002.

[84] R. N. Wagner, M. Proell, T. A. Kufer, and R. Schwarzenbacher, "Evaluation of Nod-like receptor (NLR) effector domain interactions," PLoS ONE, vol. 4, no. 4, article e4931, 2009.

[85] C. Dostert, V. Pétrilli, R. Van Bruggen, C. Steele, B. T. Mossman, and J. Tschopp, "Innate immune activation through Nalp3 inflammasome sensing of asbestos and silica," Science, vol. 320, no. 5876, pp. 674-677, 2008.

[86] A. J. Fay, X. Qian, Y. N. Jan, and L. Y. Jan, "SK channels mediate $\mathrm{NADPH}$ oxidase-independent reactive oxygen species production and apoptosis in granulocyte," Proceedings of the National Academy of Sciences of the United States of America, vol. 103, no. 46, pp. 17548-17553, 2006.

[87] J. Li and J. Yuan, "Caspases in apoptosis and beyond," Oncogene, vol. 27, no. 48, pp. 6194-6206, 2008.

[88] M. Lamkanfi and V. M. Dixit, "Inflammasomes: guardians of cytosolic sanctity," Immunological Reviews, vol. 227, no. 1, pp. 95-105, 2009.

[89] C. A. Dinarello, "Immunological and inflammatory functions of the interleukin-1 family," Annual Review of Immunology, vol. 27, pp. 519-550, 2009.

[90] T. Ichinohe, H. K. Lee, Y. Ogura, R. Flavell, and A. Iwasaki, "Inflammasome recognition of influenza virus is essential for adaptive immune responses," Journal of Experimental Medicine, vol. 206, no. 1, pp. 79-87, 2009.

[91] O. Joffre, M. A. Nolte, R. Spörri, and C. R. E. Sousa, "Inflammatory signals in dendritic cell activation and the induction of adaptive immunity," Immunological Reviews, vol. 227, no. 1, pp. 234-247, 2009.

[92] M. P. Longhi, C. Trumpfheller, and J. Idoyaga et al., "Dendritic cells require a systemic type I interferon response to mature and induce CD4+ Th1 immunity with poly IC as adjuvant," Journal of Experimental Medicine, vol. 206, no. 7, pp. 1589-1602, 2009.

[93] N. W. Palm and R. Medzhitov, "Pattern recognition receptors and control of adaptive immunity," Immunological Reviews, vol. 227, no. 1, pp. 221-233, 2009.
[94] M. Schröder and A. G. Bowie, "TLR3 in antiviral immunity: key player or bystander?” Trends in Immunology, vol. 26, no. 9, pp. 462-468, 2005.

[95] S. M. Santini, C. Lapenta, L. Santodonato, G. D’Agostino, F. Belardelli, and M. Ferrantini, "IFN-alpha in the generation of dendritic cells for cancer immunotherapy," Handbook of Experimental Pharmacology, no. 188, pp. 295-317, 2009.

[96] T. Avril, M. De Tayrac, C. Leberre, and V. Quillien, "Not all polyriboinosinic-polyribocytidylic acids (Poly I:C) are equivalent for inducing maturation of dendritic cells: Implication for $\alpha$-type-1 polarized DCs," Journal of Immunotherapy, vol. 32, no. 4, pp. 353-362, 2009.

[97] I. Tirapu, B. Giquel, and L. Alexopoulou et al., "PolyI:Cinduced reduction in uptake of soluble antigen is independent of dendritic cell activation," International Immunology, vol. 21, no. 7, pp. 871-879, 2009.

[98] S. Manicassamy and B. Pulendran, "Modulation of adaptive immunity with Toll-like receptors," Seminars in Immunology, vol. 21, no. 4, pp. 185-193, 2009.

[99] J. E. Smith-Garvin, G. A. Koretzky, and M. S. Jordan, "T cell activation," Annual Review of Immunology, vol. 27, pp. 591619, 2009.

[100] J. Taylor-Papadimitriou, J. M. Burchell, K. T. Papazisis, and H. R. Bohnenkamp, "Synergism of Toll-like receptorinduced interleukin-12p70 secretion by monocyte-derived dendritic cells is mediated through p38 MAPK and lowers the threshold of T-helper cell type 1 responses," Cellular Immunology, vol. 247, no. 2, pp. 72-84, 2007.

[101] M. C. Lebre, J. C. Antons, P. Kalinski, et al., "Double-stranded RNA-exposed human keratinocytes promote Th1 responses by inducing a Type-1 polarized phenotype in dendritic cells: role of keratinocyte-derived tumor necrosis factor alpha, type I interferons, and interleukin-18," The Journal of Investigative Dermatology, vol. 120, no. 6, pp. 990-997, 2003.

[102] A. Le Bon and D. F. Tough, "Type I interferon as a stimulus for cross-priming," Cytokine and Growth Factor Reviews, vol. 19, no. 1, pp. 33-40, 2008.

[103] K. E. Kehoe, M. A. Brown, and F. Imani, "Double-stranded RNA regulates IL-4 expression," Journal of Immunology, vol. 167, no. 5, pp. 2496-2501, 2001.

[104] C. Stahl-Hennig, M. Eisenblätter, and E. Jasny et al., "Synthetic double-stranded RNAs are adjuvants for the induction of $\mathrm{t}$ helper 1 and humoral immune responses to human papillomavirus in rhesus macaques," PLoS Pathogens, vol. 5, no. 4, article e1000373, 2009.

[105] B. Jin, R. Y. Wang, and Q. Qiu et al., "Induction of potent cellular immune response in mice by hepatitis C virus NS3 protein with double-stranded RNA," Immunology, vol. 122, no. 1, pp. 15-27, 2007.

[106] S. G. Jeon, S.-Y. Oh, and H.-K. Park et al., "TH2 and TH1 lung inflammation induced by airway allergen sensitization with low and high doses of double-stranded RNA," Journal of Allergy and Clinical Immunology, vol. 120, no. 4, pp. 803-812, 2007.

[107] O. Schulz, S. S. Diebold, and M. Chen et al., "Toll-like receptor 3 promotes cross-priming to virus-infected cells," Nature, vol. 433, no. 7028, pp. 887-892, 2005.

[108] H. Kumar, S. Koyama, K. J. Ish II, T. Kawai, and S. Akira, "Cutting edge: cooperation of IPS-1- and TRIF-dependent pathways in poly IC-enhanced antibody production and cytotoxic T cell responses," Journal of Immunology, vol. 180, no. 2, pp. 683-687, 2008. 
[109] A. Le Bon, V. Durand, and E. Kamphuis et al., "Direct stimulation of $\mathrm{T}$ cells by type I IFN enhances the CD8+ T cell response during cross-priming," Journal of Immunology, vol. 176, no. 8, pp. 4682-4689, 2006.

[110] M.-L. Lin, Y. Zhan, J. A. Villadangos, and A. M. Lew, "The cell biology of cross-presentation and the role of dendritic cell subsets," Immunology and Cell Biology, vol. 86, no. 4, pp. 353-362, 2008.

[111] M. L. Salem, C. M. Diaz-Montero, S. A. EL-Naggar, Y. Chen, O. Moussa, and D. J. Cole, "The TLR3 agonist poly(I:C) targets CD8+ T cells and augments their antigen-specific responses upon their adoptive transfer into naïve recipient mice," Vaccine, vol. 27, no. 4, pp. 549-557, 2009.

[112] F. Ghiringhelli, L. Apetoh, and A. Tesniere et al., "Activation of the NLRP3 inflammasome in dendritic cells induces IL$1 \beta$-dependent adaptive immunity against tumors," Nature Medicine, vol. 15, no. 10, pp. 1170-1178, 2009.

[113] L. E. Harrington, R. D. Hatton, and P. R. Mangan et al., "Interleukin 17-producing CD4+ effector T cells develop via a lineage distinct from the T helper type 1 and 2 lineages," Nature Immunology, vol. 6, no. 11, pp. 1123-1132, 2005.

[114] H. Park, Z. Li, and X. O. Yang et al., "A distinct lineage of CD4 $\mathrm{T}$ cells regulates tissue inflammation by producing interleukin 17," Nature Immunology, vol. 6, no. 11, pp. 11331141, 2005.

[115] P. Miossec, T. Korn, and V. K. Kuchroo, "Interleukin-17 and type 17 helper T cells," New England Journal of Medicine, vol. 361, no. 9, pp. 888-898, 2009.

[116] S. Romagnani, "Human Th17 cells," Arthritis Research and Therapy, vol. 10, no. 2, article 206, 2008.

[117] P. R. Mangan, L. E. Harrington, and D. B. O'Quinn et al., "Transforming growth factor- $\beta$ induces development of the T H17 lineage," Nature, vol. 441, no. 7090, pp. 231-234, 2006.

[118] M. Veldhoen, R. J. Hocking, C. J. Atkins, R. M. Locksley, and B. Stockinger, "TGF $\beta$ in the context of an inflammatory cytokine milieu supports de novo differentiation of IL-17producing T cells," Immunity, vol. 24, no. 2, pp. 179-189, 2006.

[119] S. Aggarwal, N. Ghilardi, M.-H. Xie, F. J. De Sauvage, and A. L. Gurney, "Interleukin-23 promotes a distinct CD4 $\mathrm{T}$ cell activation state characterized by the production of interleukin-17," Journal of Biological Chemistry, vol. 278, no. 3, pp. 1910-1914, 2003.

[120] I. I. Ivanov, B. S. McKenzie, and L. Zhou et al., "The orphan nuclear receptor ROR $\gamma \mathrm{t}$ directs the differentiation program of proinflammatory IL-17+ T helper cells," Cell, vol. 126, no. 6, pp. 1121-1133, 2006.

[121] L. Zhou, J. E. Lopes, and M. M. W. Chong et al., “TGF- $\beta$ induced Foxp 3 inhibits TH17 cell differentiation by antagonizing ROR $\gamma$ t function," Nature, vol. 453, no. 7192, pp. 236 240, 2008.

[122] N. Morishima, I. Mizoguchi, K. Takeda, J. Mizuguchi, and T. Yoshimoto, "TGF- $\beta$ is necessary for induction of IL-23R and Th17 differentiation by IL-6 and IL-23," Biochemical and Biophysical Research Communications, vol. 386, no. 1, pp. 105-110, 2009.

[123] F. Fossiez, O. Djossou, and P. Chomarat et al., "T cell interleukin-17 induces stromal cells to produce proinflammatory and hematopoietic cytokines," Journal of Experimental Medicine, vol. 183, no. 6, pp. 2593-2603, 1996.

[124] T. Seya and M. Matsumoto, "The extrinsic RNA-sensing pathway for adjuvant immunotherapy of cancer," Cancer Immunology, Immunotherapy, vol. 58, no. 8, pp. 1175-1184, 2009.
[125] S. Goriely, M. F. Neurath, and M. Goldman, "How microorganisms tip the balance between interleukin-12 family members," Nature Reviews Immunology, vol. 8, no. 1, pp. 81-86, 2008.

[126] T. Korn, E. Bettelli, M. Oukka, and V. K. Kuchroo, "IL-17 and Th17 cells," Annual Review of Immunology, vol. 27, pp. 485$517,2009$.

[127] B. Guo, E. Y. Chang, and G. Cheng, "The type I IFN induction pathway constrains Th17-mediated autoimmune inflammation in mice," Journal of Clinical Investigation, vol. 118, no. 5, pp. 1680-1690, 2008.

[128] C. K. Holm, C. C. Petersen, and M. Hvid et al., "TLR3 ligand polyinosinic: polycytidylic acid induces IL-17A and IL-21 synthesis in human Th cells," Journal of Immunology, vol. 183, no. 7, pp. 4422-4431, 2009.

[129] J. Tanaka, N. Watanabe, M. Kido, et al., "Human TSLP and TLR3 ligands promote differentiation of Th17 cells with a central memory phenotype under Th2-polarizing conditions," Clinical and Experimental Allergy, vol. 39, no. 1, pp. 89-100, 2009.

[130] J. E. Christensen and A. R. Thomsen, "Co-ordinating innate and adaptive immunity to viral infection: mobility is the key," APMIS, vol. 117, no. 5-6, pp. 338-355, 2009.

[131] B. Salaun, M. Greutert, and P. Romero, "Toll-like receptor 3 is necessary for dsRNA adjuvant effects," Vaccine, vol. 27, no. 12, pp. 1841-1847, 2009.

[132] S. M. Ngoi, M. G. Tovey, and A. T. Vella, "Targeting poly(I:C) to the TLR3-independent pathway boosts effector CD8 T cell differentiation through IFN-alpha/beta," Journal of Immunology, vol. 181, no. 11, pp. 7670-7680, 2008.

[133] T. Miyake, Y. Kumagai, and H. Kato et al., "Poly I:Cinduced activation of NK cells by CD8 alpha+ dendritic cells via the IPS-1 and TRIF-dependent pathways," Journal of Immunology, vol. 183, no. 4, pp. 2522-2528, 2009.

[134] J. Tabiasco, E. Devêvre, and N. Rufer et al., "Human effector CD8+ T lymphocytes express TLR3 as a functional coreceptor," Journal of Immunology, vol. 177, no. 12, pp. 8708-8713, 2006.

[135] Y.-F. Lau, L.-H. Tang, and E.-E. Ooi, "A TLR3 ligand that exhibits potent inhibition of influenza virus replication and has strong adjuvant activity has the potential for dual applications in an influenza pandemic," Vaccine, vol. 27, no. 9, pp. 1354-1364, 2009.

[136] J. P. Wong, M. E. Christopher, and S. Viswanathan et al., "Activation of toll-like receptor signaling pathway for protection against influenza virus infection," Vaccine, vol. 27, no. 25-26, pp. 3481-3483, 2009.

[137] J. P. Wong, M. E. Christopher, and S. Viswanathan et al., "Antiviral role of toll-like receptor-3 agonists against seasonal and avian influenza viruses," Current Pharmaceutical Design, vol. 15, no. 11, pp. 1269-1274, 2009.

[138] E. Shen, L. Li, and L. Feng et al., "PIKA as an adjuvant enhances specific humoral and cellular immune responses following the vaccination of mice with HBsAg plus PIKA," Cellular \& Molecular Immunology, vol. 4, no. 2, pp. 113-120, 2007.

[139] C. Trumpfheller, M. Caskey, and G. Nchinda et al., "The microbial mimic poly IC induces durable and protective CD4+ T cell immunity together with a dendritic cell targeted vaccine," Proceedings of the National Academy of Sciences of the United States of America, vol. 105, no. 7, pp. 2574-2579, 2008.

[140] H. Navabi, B. Jasani, and A. Reece et al., "A clinical grade poly I:C-analogue (Ampligen) promotes optimal DC maturation 
and Th1-type T cell responses of healthy donors and cancer patients in vitro," Vaccine, vol. 27, no. 1, pp. 107-115, 2009.

[141] T. Ichinohe, A. Ainai, M. Tashiro, T. Sata, and H. Hasegawa, "PolyI:polyC12U adjuvant-combined intranasal vaccine protects mice against highly pathogenic $\mathrm{H} 5 \mathrm{~N} 1$ influenza virus variants," Vaccine, vol. 27, no. 45, pp. 6276-6279, 2009.

[142] Z. Cui and F. Qiu, "CD4+ T helper cell response is required for memory in CD8+ T lymphocytes induced by a poly(I:C)adjuvanted MHC I-restricted peptide epitope," Journal of Immunotherapy, vol. 30, no. 2, pp. 180-189, 2007.

[143] A. K. Field, A. A. Tytell, G. P. Lampson, and M. R. Hilleman, "Inducers of interferon and host resistance. II. Multistranded synthetic polynucleotide complexes," Proceedings of the National Academy of Sciences of the United States of America, vol. 58, no. 3, pp. 1004-1010, 1967.

[144] G. P. Lampson, A. A. Tytell, A. K. Field, M. M. Nemes, and M. R. Hilleman, "Inducers of interferon and host resistance. I. Double-stranded RNA from extracts of Penicillium funiculosum," Proceedings of the National Academy of Sciences of the United States of America, vol. 58, no. 2, pp. 782-789, 1967.

[145] L. Alexopoulou, A. C. Holt, R. Medzhitov, and R. A. Flavell, "Recognition of double-stranded RNA and activation of NF$\kappa \mathrm{B}$ by Toll-like receptor 3," Nature, vol. 413, no. 6857, pp. 732-738, 2001.

[146] H. Kato, O. Takeuchi, and S. Sato et al., "Differential roles of MDA5 and RIG-I helicases in the recognition of RNA viruses," Nature, vol. 441, no. 1, pp. 101-105, 2006.

[147] E. De Clercq, "Antiviral drug discovery: ten more compounds, and ten more stories (Part B)," Medicinal Research Reviews, vol. 29, no. 4, pp. 571-610, 2009.

[148] M. Absher and W. R. Stinebring, "Toxic properties of a synthetic double-stranded rna: endotoxin-like properties of poly I.Poly C, an interferon stimulator," Nature, vol. 223, no. 5207, pp. 715-717, 1969.

[149] R. A. Robinson, V. T. DeVita, H. B. Levy, S. Baron, S. P. Hubbard, and A. S. Levine, "A phase I-II trial of multipledose polyriboinosic-polyribocytidylic acid in patieonts with leukemia or solid tumors," Journal of the National Cancer Institute, vol. 57, no. 3, pp. 599-602, 1976.

[150] W. A. Carter, P. M. Pitha, L. W. Marshall, I. Tazawa, S. Tazawa, and P. O. P. Ts'O, "Structural requirements of the rIn · rCn complex for Induction of human interferon," Journal of Molecular Biology, vol. 70, no. 3, pp. 567-587, 1972.

[151] D. R. Strayer, W. A. Carter, and I. Brodsky et al., "A controlled clinical trial with a specifically configured RNA drug, poly(I) · poly(C12U), in chronic fatigue syndrome," Clinical Infectious Diseases, vol. 18, supplement 1, pp. S88S95, 1994.

[152] W. A. Carter, D. R. Strayer, and I. Brodsky, "Clinical, immunological, and virological effects of ampligen, a mismatched double-stranded RNA, in patients with AIDS or AIDS-related complex," Lancet, vol. 1, no. 8545, pp. 12861292, 1987.

[153] H. B. Levy, G. Baer, and S. Baron, "A modified polyriboinosinic polyribocytidylic acid complex that induces interferon in primates," Journal of Infectious Diseases, vol. 132, no. 4, pp. 434-439, 1975.

[154] A. S. Levine and H. B. Levy, "Phase I-II trials of poly IC stabilized with poly-L-lysine," Cancer Treatment Reports, vol. 62, no. 11, pp. 1907-1912, 1978.

[155] H. X. Lin, C. Gontier, M.-F. Saron, and P. Perrin, "A new immunostimulatory complex (PICKCa) in experimental rabies: antiviral and adjuvant effects," Archives of Virology, vol. 131, no. 3-4, pp. 307-319, 1993.
[156] B. B. Gowen, M.-H. Wong, and K.-H. Jung et al., "TLR3 is essential for the induction of protective immunity against Punta Toro virus infection by the double-stranded RNA (dsRNA), poly(I:C 12U), but not poly(I:C): differential recognition of synthetic dsRNA molecules," Journal of Immunology, vol. 178, no. 8, pp. 5200-5208, 2007.

[157] D. Chaudhuri, R. Suriano, A. Mittelman, and R. K. Tiwari, "Targeting the immune system in cancer," Current Pharmaceutical Biotechnology, vol. 10, no. 2, pp. 166-184, 2009.

[158] R.-F. Wang, Y. Miyahara, and H. Y. Wang, "Toll-like receptors and immune regulation: implications for cancer therapy," Oncogene, vol. 27, no. 2, pp. 181-189, 2008.

[159] J. Galon, A. Costes, and F. Sanchez-Cabo et al., "Type, density, and location of immune cells within human colorectal tumors predict clinical outcome," Science, vol. 313, no. 5795, pp. 1960-1964, 2006.

[160] S. Ogino, K. Nosho, and N. Irahara et al., "Lymphocytic reaction to colorectal cancer is associated with longer survival, independent of lymph node count, microsatellite instability, and CpG island methylator phenotype," Clinical Cancer Research, vol. 15, no. 20, pp. 6412-6420, 2009.

[161] L. Laghi, P. Bianchi, and E. Miranda et al., "CD3+ cells at the invasive margin of deeply invading (pT3-T4) colorectal cancer and risk of post-surgical metastasis: a longitudinal study," The Lancet Oncology, vol. 10, no. 9, pp. 877-884, 2009.

[162] FDA, "Approval Letter-Provenge, April 2010 ", http:// www.fda.gov/BiologicsBloodVaccines/CellularGeneTherapy Products/ApprovedProducts/ucm210215.htm.

[163] P. H. Patel and D. R. Kockler, "Sipuleucel-T: a vaccine for metastatic, asymptomatic, androgen-independent prostate cancer," Annals of Pharmacotherapy, vol. 42, no. 1, pp. 91-98, 2008.

[164] C. S. Higano, P. F. Schellhammer, and E. J. Small et al., "Integrated data from 2 randomized, double-blind, placebocontrolled, phase 3 trials of active cellular immunotherapy with sipuleucel-T in advanced prostate cancer," Cancer, vol. 115, no. 16, pp. 3670-3679, 2009.

[165] E. J. Ilett, R. J. Prestwich, and A. A. Melcher, "The evolving role of dendritic cells in cancer therapy," Expert Opinion on Biological Therapy, vol. 10, no. 3, pp. 369-379, 2010.

[166] L. G. Durrant, V. Pudney, I. Spendlove, and R. L. Metheringham, "Vaccines as early therapeutic interventions for cancer therapy: neutralising the immunosuppressive tumour environment and increasing $\mathrm{T}$ cell avidity may lead to improved responses," Expert Opinion on Biological Therapy, vol. 10, no. 5, pp. 735-748, 2010.

[167] A. Makkouk and A. M. Abdelnoor, "The potential use of toll-like receptor (TLR) agonists and antagonists as prophylactic and/or therapeutic agents," Immunopharmacology and Immunotoxicology, vol. 31, no. 3, pp. 331-338, 2009.

[168] B. Salaun, I. Coste, M.-C. Rissoan, S. J. Lebecque, and T. Renno, "TLR3 can directly trigger apoptosis in human cancer cells," Journal of Immunology, vol. 176, no. 8, pp. 4894-4901, 2006.

[169] T. Matijevic, M. Marjanovic, and J. Pavelic, "Functionally active toll-like receptor 3 on human primary and metastatic cancer cells," Scandinavian Journal of Immunology, vol. 70, no. 1, pp. 18-24, 2009.

[170] A. Paone, D. Starace, R. Galli, et al., "Toll-like receptor 3 triggers apoptosis of human prostate cancer cells through a PKC-alpha-dependent mechanism," Carcinogenesis, vol. 29, no. 7, pp. 1334-1342, 2008.

[171] K. Yoneda, K. Sugimoto, and K. Shiraki et al., "Dual topology of functional Toll-like receptor 3 expression in human 
hepatocellular carcinoma: differential signaling mechanisms of TLR3-induced NF- $\kappa$ B activation and apoptosis," International Journal of Oncology, vol. 33, no. 5, pp. 929-936, 2008.

[172] B. Salaun, S. Lebecque, S. Matikainen, D. Rimoldi, and P. Romero, "Toll-like receptor 3 expressed by melanoma cells as a target for therapy?" Clinical Cancer Research, vol. 13, no. 15, pp. 4565-4574, 2007.

[173] M. Zhou, M. M. McFarland-Mancini, H. M. Funk, N. Husseinzadeh, T. Mounajjed, and A. F. Drew, "Toll-like receptor expression in normal ovary and ovarian tumors," Cancer Immunology, Immunotherapy, vol. 58, no. 9, pp. 13751385, 2009.

[174] B. Jasani, H. Navabi, and M. Adams, "Ampligen: a potential toll-like 3 receptor adjuvant for immunotherapy of cancer," Vaccine, vol. 27, no. 25-26, pp. 3401-3404, 2009.

[175] H. B. Levy, "Historical overview of the use of polynucleotides in cancer," Journal of Biological Response Modifiers, vol. 4, no. 5, pp. 475-480, 1985.

[176] N. Butowski, S. M. Chang, and L. Junck et al., "A phase II clinical trial of poly-ICLC with radiation for adult patients with newly diagnosed supratentorial glioblastoma: a North American Brain Tumor Consortium (NABTC01-05)," Journal of Neuro-Oncology, vol. 91, no. 2, pp. 175-182, 2009.

[177] N. Butowski, K. R. Lamborn, and B. L. Lee et al., "A North American brain tumor consortium phase II study of polyICLC for adult patients with recurrent anaplastic gliomas," Journal of Neuro-Oncology, vol. 91, no. 2, pp. 183-189, 2009.

[178] A. S. Levine, M. Sivulich, P. H. Wiernik, and H. B. Levy, "Initial clinical trials in cancer patients of polyriboinosinicpolyribocytidylic acid stabilized with poly-L-lysine, in carboxymethylcellulose [poly(ICLC)], a highly effective interferon inducer," Cancer Research, vol. 39, no. 5, pp. 1645-1650, 1979.

[179] C. H. Ewel, W. J. Urba, and W. C. Kopp et al., "Polyinosinicpolycytidylic acid complexed with poly-L-lysine and carboxymethylcellulose in combination with interleukin 2 in patients with cancer: clinical and immunological effects," Cancer Research, vol. 52, no. 11, pp. 3005-3010, 1992.

[180] B. J. Giantonio, H. Hochster, and R. Blum et al., "Toxicity and response evaluation of the interferon inducer poly ICLC administered at low dose in advanced renal carcinoma and relapsed or refractory lymphoma: a report of two clinical trials of the eastern cooperative oncology group," Investigational New Drugs, vol. 19, no. 1, pp. 89-92, 2001.

[181] A. E. Maluish, J. W. Reid, and E. A. Crisp, "Immunomodulatory effects of poly(I,C)-LC in cancer patients," Journal of Biological Response Modifiers, vol. 4, no. 6, pp. 656-663, 1985.

[182] X. Zhu, F. Nishimura, and K. Sasaki et al., "Toll like receptor3 ligand poly-ICLC promotes the efficacy of peripheral vaccinations with tumor antigen-derived peptide epitopes in murine CNS tumor models," Journal of Translational Medicine, vol. 5, article 10, 2007.

[183] H. Okada, "Brain tumor immunotherapy with type-1 polarizing strategies," Annals of the New York Academy of Sciences, vol. 1174, pp. 18-23, 2009.

[184] H. C. Jeung, Y. W. Moon, and S. Y. Rha, "Phase III trial of adjuvant 5-fluorouracil and adriamycin versus 5fluorouracil, adriamycin, and polyadenylic-polyuridylic acid (poly A:U) for locally advanced gastric cancer after curative surgery: final results of 15-year follow-up," Annals of Oncology, vol. 19, no. 3, pp. 520-526, 2008.

[185] J. Lacour, A. Laplanche, and M. Malafosse et al., "Polyadenylic-polyuridylic acid as an adjuvant in resectable colorectal carcinoma: a $61 / 2$ year follow-up analysis of a multicentric double blind randomized trial," European Journal of Surgical Oncology, vol. 18, no. 6, pp. 599-604, 1992.

[186] L. Wang, D. Smith, S. Bot, L. Dellamary, A. Bloom, and A. Bot, "Noncoding RNA danger motifs bridge innate and adaptive immunity and are potent adjuvants for vaccination," Journal of Clinical Investigation, vol. 110, no. 8, pp. 11751184, 2002.

[187] A. Bot, D. Smith, B. Phillips, S. Bot, C. Bona, and H. Zaghouani, "Immunologic control of tumors by in vivo Fc gamma receptor-targeted antigen loading in conjunction with double-stranded RNA-mediated immune modulation," Journal of Immunology, vol. 176, no. 3, pp. 1363-1374, 2006.

[188] T. Sugiyama, K. Hoshino, and M. Saito et al., "Immunoadjuvant effects of polyadenylic: polyuridylic acids through TLR3 and TLR7," International Immunology, vol. 20, no. 1, pp. 1-9, 2008.

[189] B. Huang, J. Zhao, J. C. Unkeless, Z. H. Feng, and H. Xiong, "TLR signaling by tumor and immune cells: a double-edged sword," Oncogene, vol. 27, no. 2, pp. 218-224, 2008.

[190] R. Chen, A. B. Alvero, D.-A. Silasi, K. D. Steffensen, and G. Mor, "Cancers take their Toll-the function and regulation of Toll-like receptors in cancer cells," Oncogene, vol. 27, no. 2, pp. 225-233, 2008.

[191] M. Lehoux, C. M. D’Abramo, and J. Archambault, "Molecular mechanisms of human papillomavirus-induced carcinogenesis," Public Health Genomics, vol. 12, no. 5-6, pp. 268280, 2009.

[192] F. H. Pujol, M.-C. Navas, P. Hainaut, and I. Chemin, "Worldwide genetic diversity of HBV genotypes and risk of hepatocellular carcinoma," Cancer Letters, vol. 286, no. 1, pp. 80-88, 2009.

[193] E. L. Franco, F. Coutlée, and A. Ferenczy, "Integrating human papillomavirus vaccination in cervical cancer control programmes," Public Health Genomics, vol. 12, no. 5-6, pp. 352-361, 2009.

[194] S. G. Lim, R. Mohammed, M.-F. Yuen, and J.-H. Kao, "Prevention of hepatocellular carcinoma in hepatitis B virus infection," Journal of Gastroenterology and Hepatology, vol. 24, no. 8, pp. 1352-1357, 2009.

[195] A. Plymoth, S. Viviani, and P. Hainaut, "Control of hepatocellular carcinoma through Hepatitis B vaccination in areas of high endemicity: perspectives for global liver cancer prevention," Cancer Letters, vol. 286, no. 1, pp. 15-21, 2009.

[196] A. H. Sherker, "ACP Journal Club. Review: interferon and nucleoside/tide analogues reduce risk for hepatocellular cancer in patients with chronic hepatitis B," Annals of Internal Medicine, vol. 150, no. 8, pp. 4-11, 2009.

[197] W. P. Drake, W. J. Pendergrast Jr., and M. R. Mardiney Jr., "Enhancement of spontaneous $\mathrm{C} 3 \mathrm{H} / \mathrm{HeJ}$ mammary tumorigenesis by long term polyadenylic polyuridylic acid therapy," Cancer Research, vol. 35, no. 11 I, pp. 3051-3053, 1975.

[198] F. Stenback, G. Curtis, and W. Ryan, "Polyadenylatepolyuridylate enhancement of 7,12-dimethylbenzanthracene skin carcinogenesis," Experientia, vol. 35, no. 9, pp. 1232-1233, 1979.

[199] H. Liu, M. Komai-Koma, D. Xu, and F. Y. Liew, "Toll-like receptor 2 signaling modulates the functions of $\mathrm{CD} 4{ }^{+} \mathrm{CD} 25^{+}$ regulatory T cells," Proceedings of the National Academy of Sciences of the United States of America, vol. 103, no. 18, pp. 7048-7053, 2006. 
[200] R. P. M. Sutmuller, M. H. M. G. M. Den Brok, and M. Kramer et al., "Toll-like receptor 2 controls expansion and function of regulatory T cells," Journal of Clinical Investigation, vol. 116, no. 2, pp. 485-494, 2006.

[201] E. M. El-Omar, M. T. Ng, and G. L. Hold, "Polymorphisms in Toll-like receptor genes and risk of cancer," Oncogene, vol. 27, no. 2, pp. 244-252, 2008.

[202] M. Fukata and M. T. Abreu, "Role of Toll-like receptors in gastrointestinal malignancies," Oncogene, vol. 27, no. 2, pp. 234-243, 2008.

[203] U. K. Scarlett, J. R. Cubillos-Ruiz, and Y. C. Nesbeth et al., "In situ stimulation of CD40 and toll-like receptor 3 transforms ovarian cancer-infiltrating dendritic cells from immunosuppressive to immunostimulatory cells," Cancer Research, vol. 69, no. 18, pp. 7329-7337, 2009.

[204] Y. Zhang, R. Sun, and B. Liu et al., "TLR3 activation inhibits nasopharyngeal carcinoma metastasis via downregulation of chemokine receptor CXCR4," Cancer Biology and Therapy, vol. 8, no. 19, pp. 1826-1830, 2010.

[205] K. Karikó, H. Ni, J. Capodici, M. Lamphier, and D. Weissman, "mRNA is an endogenous ligand for Toll-like receptor 3," Journal of Biological Chemistry, vol. 279, no. 13, pp. 12542-12550, 2004.

[206] J. Andrejeva, K. S. Childs, and D. F. Young et al., "The V proteins of paramyxoviruses bind the IFN-inducible RNA helicase, mda-5, and inhibit its activation of the IFN- $\beta$ promoter," Proceedings of the National Academy of Sciences of the United States of America, vol. 101, no. 49, pp. 1726417269, 2004.

[207] P. M. Barral, D. Sarkar, P. B. Fisher, and V. R. Racaniello, "RIG-I is cleaved during picornavirus infection," Virology, vol. 391, no. 2, pp. 171-176, 2009.

[208] A. Arjona, M. Ledizet, and K. Anthony et al., "West Nile virus envelope protein inhibits dsRNA-induced innate immune responses," Journal of Immunology, vol. 179, no. 12, pp. 84038409, 2007.

[209] D. Alonso-Curbelo and M. S. Soengas, "Self-killing of melanoma cells by cytosolic delivery of dsRNA: wiring innate immunity for a coordinated mobilization of endosomes, autophagosomes and the apoptotic machinery in tumor cells," Autophagy, vol. 6, no. 1, pp. 148-150, 2010. 


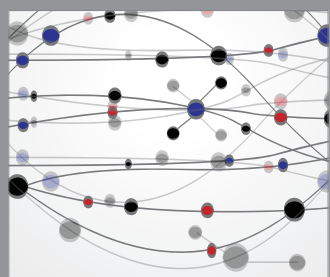

The Scientific World Journal
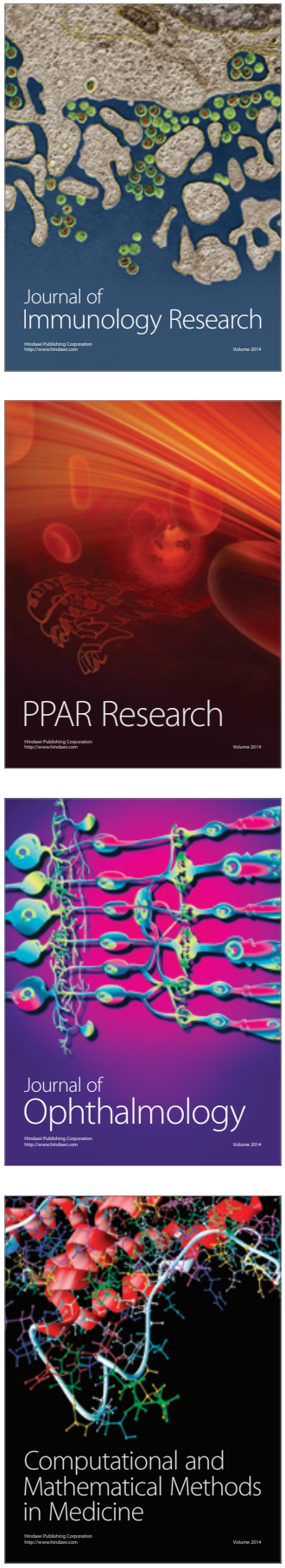

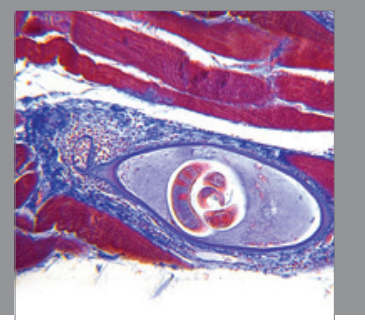

Gastroenterology

Research and Practice
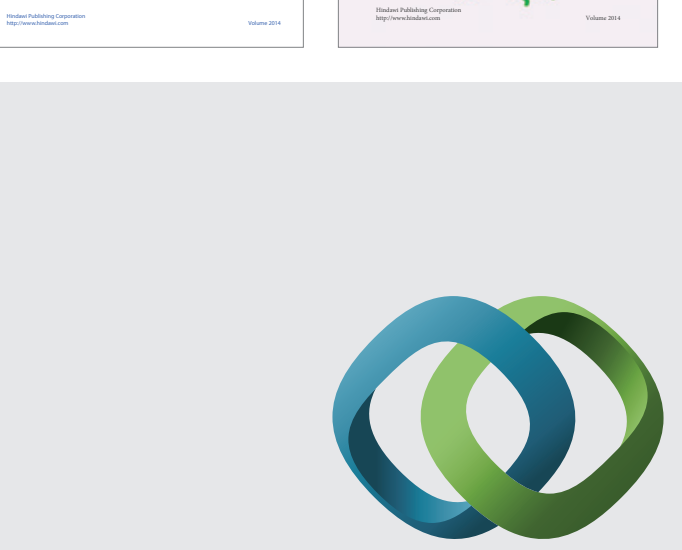

\section{Hindawi}

Submit your manuscripts at

http://www.hindawi.com
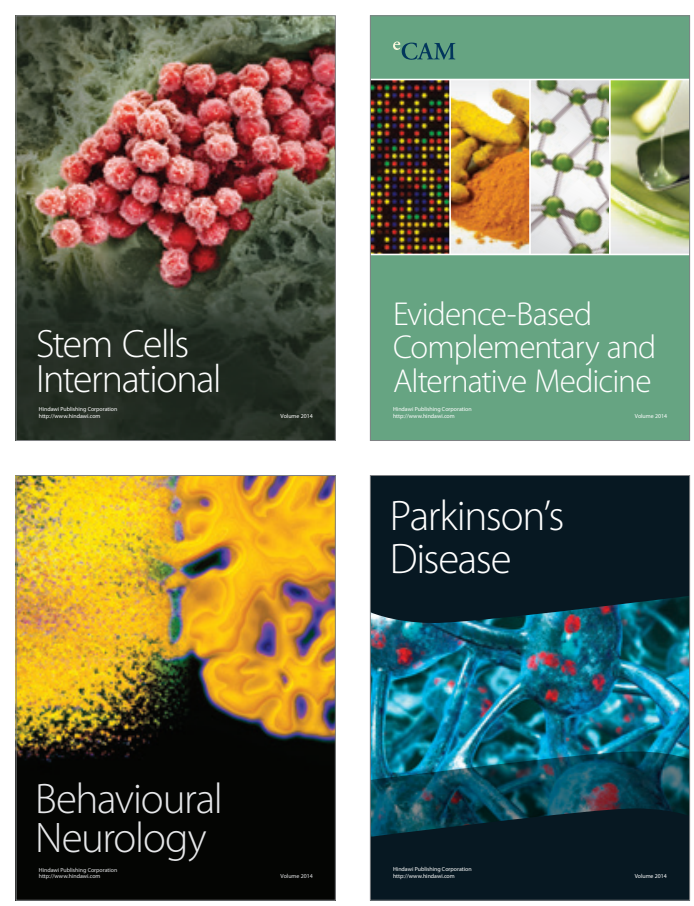

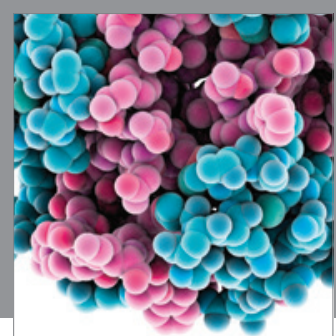

Journal of
Diabetes Research

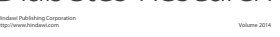

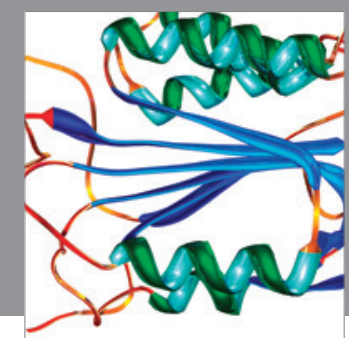

Disease Markers
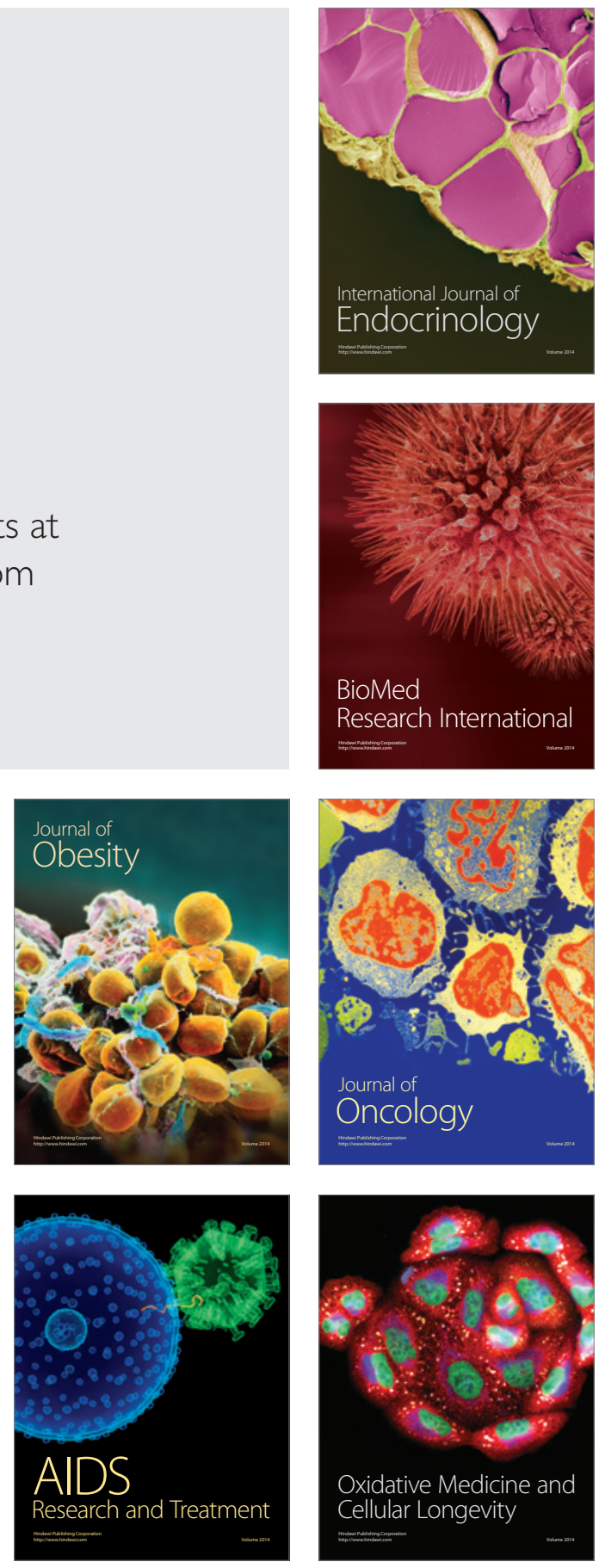